Universidade de São Paulo

Escola Superior de Agricultura "Luiz de Queiroz"

\title{
Utilização de própolis e probiótico em dietas para leitões recém-
} desmamados

\section{Natália Yumi Ikeda}

\author{
Dissertação apresentada para obtenção do título de \\ Mestra em Ciências. Área de concentração: Ciência \\ Animal e Pastagens
}

\section{Piracicaba}




\section{Natália Yumi Ikeda}

Zootecnista

Utilização de própolis e probiótico em dietas para leitões recém-desmamados

Orientador:

Prof. Dr. VALDOMIRO SHIGUERU MIYADA

Dissertação apresentada para obtenção do título de Mestra em Ciências. Área de concentração: Ciência Animal e Pastagens 


\section{Dados Internacionais de Catalogação na Publicação DIVISÃO DE BIBLIOTECA - DIBD/ESALQ/USP}

Ikeda, Natália Yumi

Utilização de própolis e probiótico em dietas para leitões recém-desmamados / Natália Yumi lkeda. - - Piracicaba, 2015.

75 p. : il.

Dissertação (Mestrado) - - Escola Superior de Agricultura "Luiz de Queiroz".

1. Aditivo natural 2. Desempenho 3. Digestibilidade 4. Órgãos 5. Microbiota intestinal I. Título

CDD 636.4085

$126 \mathrm{u}$

"Permitida a cópia total ou parcial deste documento, desde que citada a fonte - O autor" 


\section{DEDICATÓRIA}

À vida,

por vezes não entendi os seus sinais, coincidências não acontecem.

Ao meu avô,

\section{Massanori Yokoi,}

por incentivar a continuar a estudar, isso ninguém tira de você.

Ao meu pai,

\section{Shyoji Ikeda,}

por ensinar o sentido das palavras compromisso e responsabilidade, e a importância da família, sem ela não somos nada.

À minha mãe,

\section{Rosa Setsuko Yokoi Ikeda,}

que com carinho ensinou a perseverar e ter paciência e sabedoria para lidar com situações difíceis, não vale a pena carregar certas coisas.

Ao meu irmão,

\section{Mikio Yokoi Ikeda,}

por acrescentar com inimagináveis diferentes pontos de vista, às vezes não é bem o que imaginamos.

Ao meu irmão caçula,

\section{Yuki Yokoi Ikeda,}

que com alegria sempre incentivou a ser o que sou, eu me espelho em você.

Ao meu grande amigo e companheiro,

\section{Fabio Henrique Takahashi,}

que com muita paciência nunca deixou de acreditar em mim, não se subestime nunca. 


\section{AGRADECIMENTOS}

À Escola Superior de Agricultura "Luiz de Queiroz" - ESALQ - Universidade de São Paulo, pela oportunidade em realizar o mestrado e conhecer a cidade de Piracicaba.

Ao Prof. Dr. Valdomiro Shigueru Miyada (ESALQ), pelos ensinamentos e auxílio na condução do experimento.

Ao Prof. Dr. José Fernando Machado Menten (ESALQ), pelos ensinamentos e questionamentos.

Ao Dr. Maicon Sbardella, pela imensa paciência e enriquecimento em detalhes científicos.

Ao Prof. Dr. Ricardo de Oliveira Orsi (UNESP - Botucatu), pela introdução ao "mundo das abelhas" e pelo grande incentivo em investir no mestrado.

Às Profas. Dra. Ana Sílvia Alves Tavares Moura e Simone Fernandes (UNESP - Botucatu), por contribuírem no meu ingresso no mestrado.

Aos funcionários do Setor de Suinocultura (ESALQ), Gilberto Antonio Aliberti Júnior "Giba", Leonilço Ramos "Leo" e José Pires Alves Sobrinho "Seu Pires", por também zelarem pela condução do experimento.

Aos funcionários do Departamento de Zootecnia (ESALQ), Antônio Carlos Oliva, Gilberto da Silva Duarte e José Augusto Alves, pelo auxílio na confecção das dietas; José Henrique Rocha, pela prontidão; José Kossut Knapik e Paulo Marcos de Oliveira, pelo auxílio durante o experimento, Sandra Vicente Augusto e Silvia Adriana Tibério, pelos muitos recados e lembretes.

Aos técnicos do Laboratório de Nutrição e Crescimento Animal (ESALQ), Maria Antonia Ladalardo Etchegay e Daniel Messias Ribeiro, por disponibilizar local para o preparo de soluções.

Ao técnico do Laboratório de Química (ESALQ), Luis Humberto Gomes, pela indicação de um laboratório para a realização das análises microbiológicas.

Ao colega, Franz Gois, por direcionar a preparação dos protocolos para as análises microbiológicas.

À Profa. Dra. Maria Carolina Quecine Verdi (ESALQ), pelo entusiasmo e disposição em auxiliar na condução das análises microbiológicas.

Ao técnico do Laboratório de Genética de Microrganismos (ESALQ), José Antônio da Silva "Zezo", pelo auxílio na realização das análises microbiológicas e grande apoio motivacional.

À equipe do Laboratório de Anatomia e Fisiologia Animal (ESALQ), Prof. Dr. Raul Machado Neto, por disponibilizar laboratório e equipe para realização da leitura das lâminas histológicas; Dra. Débora Botéquio Moretti, pelo auxílio na utilização dos equipamentos para leitura das lâminas. 
À aluna de graduação em Engenharia Agronômica, Caroline Batista dos Santos, pela disposição e auxílio na condução do experimento.

À equipe do Laboratório de Bioquímica e Análise Instrumental (ESALQ), Prof. Dr. Severino Matias de Alencar, por disponibilizar laboratório e equipe para a realização das análises de caracterização e qualidade da própolis; técnicas Ivani Aparecida Marchetto Moreno e Adna Prado Massariolio, pela disposição e auxílio na realização das análises; aos pós-graduandos Thalita Riquelme Augusto, Luciano Henrique Campestrini, Fernanda Francetto Juliano, pela disposição e auxílio na realização das análises de caracterização da própolis que enriqueceram o experimento.

À equipe do Laboratório de Bromatologia e Minerais, Instituto de Zootecnia - IZ, Nova Odessa - SP, Dra. Rosana Aparecida Possenti e Patrícia Brás, pela atenção e realização das análises bromatológicas.

À equipe do Laboratório Multiusuário em Produção Vegetal (ESALQ), Dr. Tiago Tezotto, pela disposição e realização das análises de quantificação do marcador óxido de cromo.

À equipe da HISTOTECH Lâminas Didáticas, Margareth T. Arroyo e Cláudio Arroyo, pela atenção e confecção das lâminas histológicas.

À CONAP, por contribuir com a própolis utilizada no experimento, em especial ao Cristiano Carvalho, pelo interesse na pesquisa e intermédio na obtenção do produto.

À empresa IMEVE, por contribuir com o probiótico utilizado no experimento.

À amiga e colega, Natália Cristina Milani, pela disposição e imenso apoio motivacional, por elevar minha coragem e espírito.

Aos colegas de departamento (ESALQ), José Guilherme Morschel Barbosa e Cristiano Bortoluzzi, pela disposição e auxílio na condução do experimento.

Aos meus familiares, famílias Ikeda e Yokoi, pelo incentivo e motivação, em especial as minhas queridas tias Misao Ikeda e Emiko Ikeda, por sempre enaltecerem quem eu sou e ensinarem que os laços familiares devem ser cultivados e preservados.

Às amigas, Letícia Faria de Abreu e Lígia Uribe Gonçalves, por partilharem conquistas e vitórias e ensinarem a dar valor os que somos e ao que fazemos.

Ao pessoal das aulas de espanhol, Prof. Ivan Pezoa Opazo, pelo enriquecimento cultural e vibrante torcida; Giordano Bruno S. Saiter, Armando Kaieda e José Guilherme Morschel Barbosa, pelas risadas e palavras de incentivo.

À professora de japonês, Kelly Stenico, por retomar minhas origens e ensinar o significado de priorizar.

Aos amigos, que contando agora são muitos, pelo incondicional apoio e pelas inúmeras e divertidas mensagens de apoio. 


\section{BIOGRAFIA}

NATÁLIA YUMI IKEDA, filha de Shyoji Ikeda e Rosa Setsuko Yokoi Ikeda, nasceu em São Paulo - SP, em 5 de maio de 1986.

Realizou ensino básico, fundamental e médio no Colégio Dimensão, São Paulo - SP.

Em julho de 2005, ingressou no curso de graduação em Zootecnia na Universidade Estadual Paulista "Júlio de Mesquita Filho” (UNESP), Câmpus Ilha Solteira.

Em fevereiro de 2007, transferiu para o curso de graduação em Zootecnia na Universidade Estadual Paulista "Júlio de Mesquita Filho" (UNESP), Câmpus Botucatu, onde em 12 de novembro de 2010 obteve o título de Zootecnista. No ano de 2010, realizou pesquisa de iniciação científica e foi bolsista da Fundação de Amparo a Pesquisa do Estado de São Paulo (FAPESP).

No período de julho de 2011 a fevereiro de 2013, atuou como revisora de tradução na empresa ADTRANS Intercom Serviços de Texto Ltda.

Em julho de 2013, ingressou no curso de Mestrado do Programa de Pós-Graduação em "Ciência Animal e Pastagens" da Escola Superior de Agricultura "Luiz de Queiroz" (ESALQ), Universidade de São Paulo (USP), sendo bolsista CAPES. 
"In order to be irreplaceable one must always be different"

Coco Chanel

"Keep moving forward"

Walt Disney 


\section{SUMÁRIO}

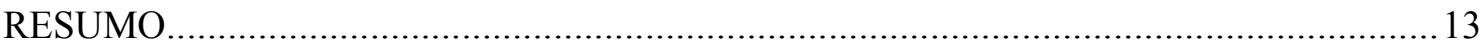



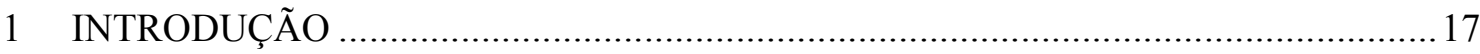



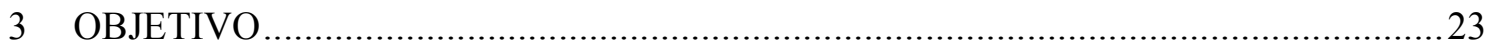

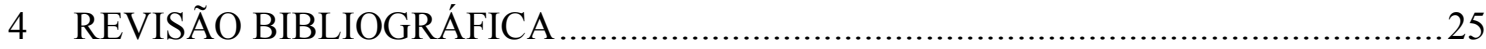

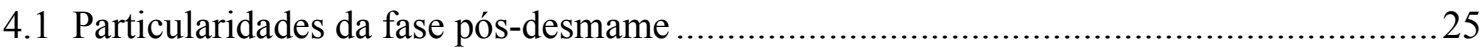

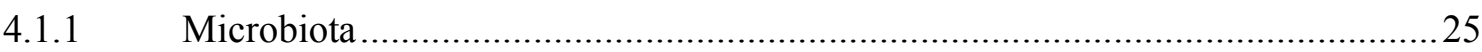

4.2 Aditivos em dietas de leitões ................................................................................2

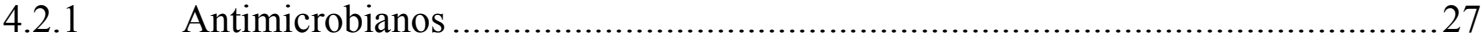

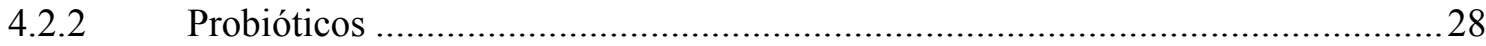

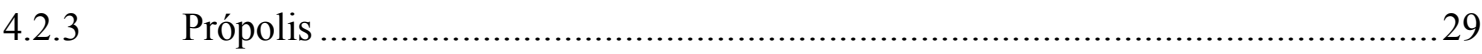

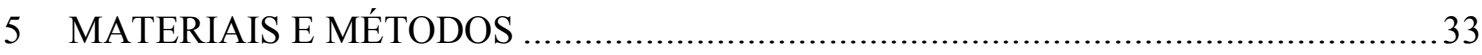

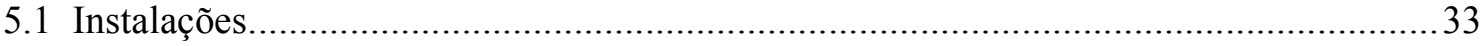

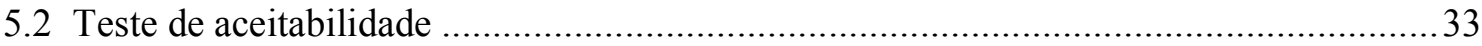

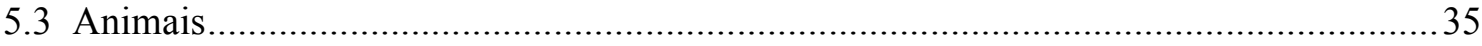

5.4 Manejo

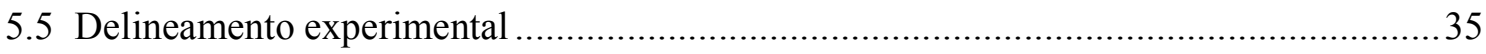





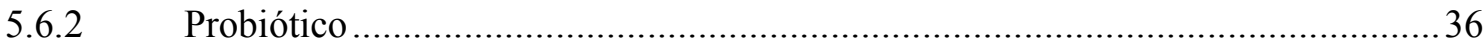

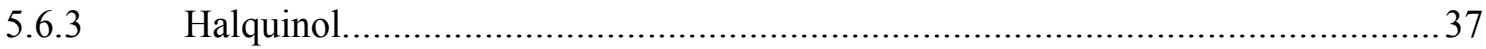

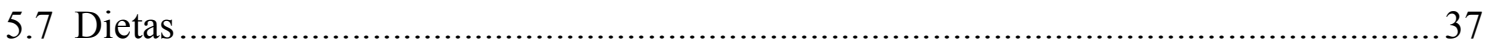

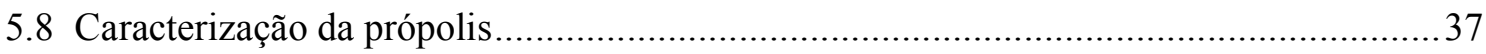



5.8.2 Determinação do teor de compostos fenólicos totais .............................................37

5.8.3 Determinação do teor de flavonoides totais......................................................38

5.8.4 Determinação da atividade antioxidante pelo método ABTS+.............................38

5.8.5 Cromatografia em camada delgada (CCD)....................................................... 39

5.9 Análises bromatológicas e energia das dietas e fezes ...................................................39

5.10 Digestibilidade aparente dos nutrientes e energia bruta ……………………................40

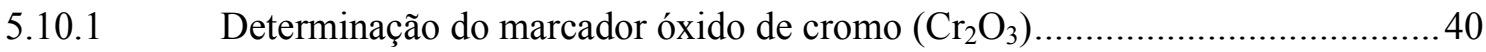




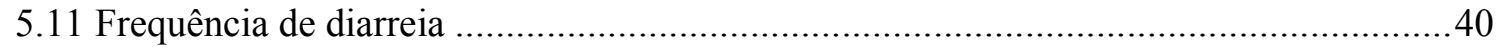

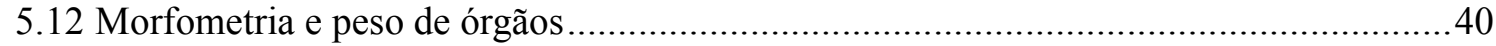

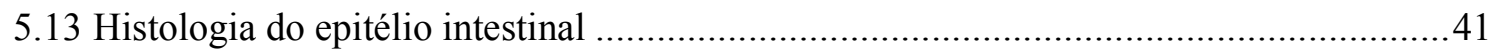

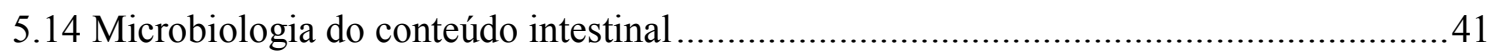

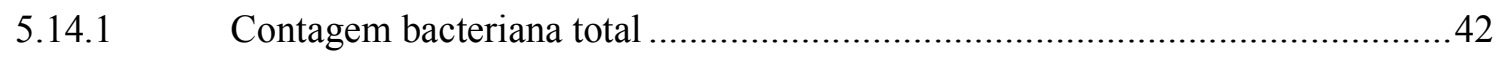

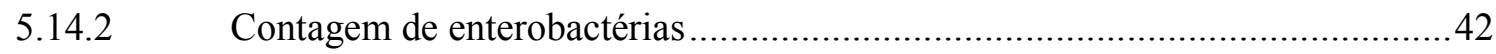

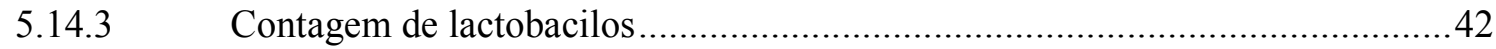

5.14.4 Análise dos dados de microbiologia ..............................................................43

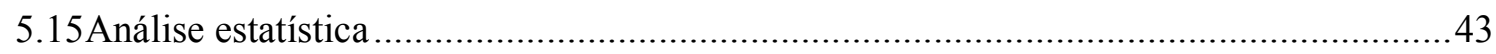

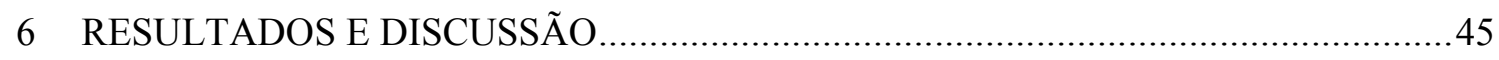

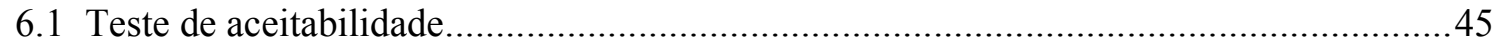

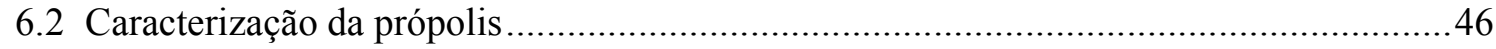



6.4 Digestibilidade aparente dos nutrientes e energia bruta ..........................................49

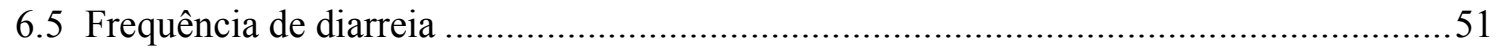

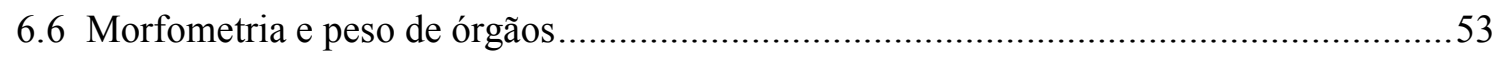



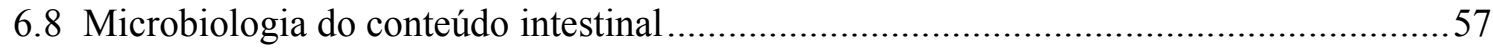

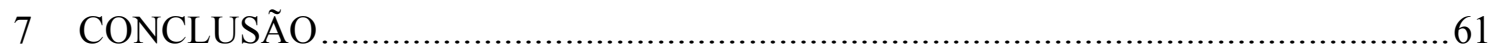






\section{RESUMO}

\section{Utilização de própolis e probiótico em dietas para leitões recém-desmamados}

A restrição ao uso de antimicrobianos melhoradores de desempenho em dietas animais, em consequência de preocupações relacionadas à qualidade e segurança dos alimentos, estimula a procura por aditivos alternativos naturais. Com o intuito de investigar aditivos alternativos naturais na nutrição de leitões recém-desmamados, o objetivo deste projeto de pesquisa foi estudar os efeitos independentes e da combinação da própolis bruta e do probiótico, adicionados em dietas para leitões recém-desmamados, sobre o desempenho zootécnico, a frequência de diarreia, a digestibilidade dos nutrientes e energia da dieta, a morfometria e peso de órgãos (digestórios e baço), a histologia do epitélio intestinal (altura de vilosidade, profundidade de cripta e relação vilosidade:cripta) e a microbiologia do conteúdo intestinal (plaqueamento em placa de ágar), em comparação ao uso de um antimicrobiano melhorador de desempenho (clorohidroxiquinilina). Foram utilizados 120 leitões recémdesmamados em um experimento em blocos completos casualizados com cinco tratamentos, oito repetições (blocos) por tratamento e três animais por unidade experimental (baia). Os tratamentos foram distribuídos aleatoriamente dentro de cada bloco, obedecendo a um esquema fatorial $2 \times 2+1$, sendo: controle (dieta basal sem adição de aditivos); própolis (dieta basal com $0,4 \%$ de própolis bruta); probiótico (dieta basal com $0,1 \%$ de probiótico); própolis + probiótico (dieta basal com $0,4 \%$ de própolis bruta e $0,1 \%$ de probiótico) e antimicrobiano (dieta basal com antimicrobiano). As dietas e a água foram fornecidas à vontade durante o período experimental de 35 dias. Os animais foram pesados no $1^{\circ}, 7^{\circ}, 21^{\circ}$ e $35^{\circ}$ dia do experimento. A ocorrência de diarreia foi registrada diariamente. Ao final do período experimental, um animal de cada baia foi abatido para a realização da morfometria e pesagem de órgãos, histologia do epitélio intestinal e microbiologia do conteúdo intestinal. Os dados foram analisados pelo procedimento MIXED do SAS e as médias comparadas pelo teste de Dunnett, comparando o tratamento antimicrobiano com os outros tratamentos. A inclusão de própolis bruta e probiótico, isolados ou em combinação, não afetou o desempenho, a frequência de diarreia e a histologia do epitélio intestinal. A própolis influenciou negativamente na digestibilidade aparente do extrativo não nitrogenado $(\mathrm{p}<0,05)$. A própolis $\mathrm{e}$ o probiótico, isolados ou em combinação, também influenciaram negativamente na digestibilidade de todos os nutrientes e na energia bruta das dietas em comparação à utilização de antimicrobiano $(\mathrm{p}<0,05)$. A combinação de própolis e probiótico promoveu aumento do peso absoluto e relativo do intestino delgado em comparação ao tratamento antimicrobiano $(\mathrm{p}<0,05)$. No conteúdo intestinal do jejuno, a inclusão do probiótico aumentou a contagem de bactérias do gênero Enterococcus $(\mathrm{p}<0,05)$. Entretanto, a própolis diminuiu a contagem de bactérias do gênero Lactobacillus $(\mathrm{p}<0.05)$. No conteúdo do ceco, a própolis bruta isolada promoveu contagem de bactérias do gênero Enterococcus superior em relação ao tratamento antimicrobiano $(\mathrm{p}<0,05)$. E o tratamento antimicrobiano diminuiu a contagem de bactérias do gênero Lactobacillus em comparação aos outros taratamentos $(\mathrm{p}<0,05)$. A inclusão de própolis bruta e probiótico, isolados ou em combinação, não melhorou o desempenho de leitões recém-desmamados em comparação ao tratamento antimicrobiano neste exprimento.

Palavras-chaves: Aditivo natural; Desempenho; Digestibilidade; Órgãos; Microbiota intestinal 


\section{ABSTRACT \\ Use of propolis and probiotic in newly weaned pigs diets}

Antimicrobial growth promoter restriction in animal diets due to safety concerns enhanced the research of natural feed additive alternatives. In order to search for natural feed additive alternatives for weanling pigs, this study investigated independent and combined dietary effects of crude propolis and probiotic on weanling pigs' performance, diarrhea, nutrients and energy digestibility, organ weights (digestive organs and spleen), intestinal epithelium histology (villus height, crypt depth and villus:crypt ratio), and intestinal microbial counts (agar plating assay) in comparison to an antimicrobial growth promoter (chlorohydroxiquinoline). One hundred and twenty 21-d weaned pigs were allotted in a randomized complete block design experiment with five treatments, eight replications and three animals per experimental unit (pen). Treatments, arranged in a $2 \times 2+1$ factorial design, were: control treatment consisted in a basal diet without any additive; propolis, basal diet with $0.4 \%$ of crude propolis; probiotic, basal diet with $0.1 \%$ of probiotic; propolis + probiotic, basal diet with $0.4 \%$ of crude propolis and $0.1 \%$ of probiotic and antimicrobial treatment, basal diet with antimicrobial growth promoter. Feed and water were given ad libitum during a 35-d nursery feeding experiment. Animals were weighed at d 0, 7, 21 and 35 of experiment. Diarrhea occurrence was registered every day. At the end of experimental period, an animal per pen was slaughtered for analyses of organ weights, intestinal epithelium histology and intestinal microbial counts. Data was analyzed by using the MIXED procedure of SAS. Dunnett test was used to compare antimicrobial treatment with each other treatment. Dietary crude propolis and probiotic inclusion, isolated and combined, did not affected weanling pigs' growth performance, diarrhea occurrence and intestinal epithelium histology. Dietary propolis reduced nitrogen-free extract digestibility $(\mathrm{p}<0.05)$. Dietary propolis and probiotic, isolated and combined, negatively affected nutrients and energy digestibility compared to antimicrobial treatment $(\mathrm{p}<0.05)$. Propolis and probiotic combination increased small intestine weight in comparison to antimicrobial treatment $(\mathrm{p}<0.05)$. In jejunum content, dietary probiotic increased Enterococcus sp. counts $(\mathrm{p}<0.05)$, while dietary propolis decreased Lactobacillus sp. counts $(\mathrm{p}<0.05)$. In cecum content, isolated propolis had higher Enterococcus sp. counts compared to antimicrobial $(\mathrm{p}<0.05)$. Moreover, antimicrobial treatment lowered Lactobacillus sp. counts compared to all other treatments $(\mathrm{p}<0.05)$. Overall, dietary propolis and probiotic, isolated and combined, did not enhanced growth performance compared to antimicrobial treatment in the present study.

Keywords: Natural feed additive; Performance; Digestibility; Organs; Microbial counts 


\section{INTRODUÇÃO}

$\mathrm{Na}$ suinocultura industrial, a intensa procura para maximizar a quantidade anual de carne produzida por matriz alojada promoveu esforços para a melhoria na genética dos animais e nos processos de produção. Dentre os processos de produção, o desmame precoce de leitões, em média aos 21 dias de idade, foi adotado com o intuito de possibilitar com que as matrizes iniciem um novo ciclo produtivo o mais breve possível e, dessa forma, produzam um maior número de leitões por ano (GIROUX; GUY-PIERRE; ROBERT, 2000; ROBERT; WEARY; GONYOU, 1999; SILVA et al., 2008).

A fase imediatamente após o desmame é uma das mais críticas no desenvolvimento dos suínos em razão do sistema digestório estar pouco adaptado ao aproveitamento de alimentos sólidos, tendo, como agravantes, fatores estressantes como a separação dos leitões da matriz, a mudança de ambiente, o reagrupamento de animais de diferentes leitegadas e a mudança brusca na alimentação (DE ANGELIS et al., 2006; SANTOS et al., 2003; SCANDOLERA et al., 2008; SILVA et al., 2008). Nesta fase, a imaturidade digestiva propicia a colonização do trato gastrintestinal por microrganismos patogênicos, favorecendo a ocorrência de diarreia, comprometendo o desempenho e aumentando os índices de morbidade e mortalidade (DE ANGELIS et al., 2006; OETTING et al., 2006).

Com o intuito de minimizar tais efeitos deletérios, tem sido comum o uso de antimicrobianos melhoradores de desempenho em dietas para suínos recém-desmamados, na tentativa de eliminar ou controlar microrganismos que prejudicam o desempenho animal (DIBNER; RICHARDS, 2005; GASKINS et al., 2002; MENTEN, 2002; OETTING et al., 2006; PAGE, 2006; PEDROSO et al., 2005). Ainda que comprovada sua capacidade de melhorar o desempenho de suínos, o uso de antimicrobianos melhoradores de desempenho tem sido restringido em diversos países, induzindo a realização de pesquisas na busca por novas alternativas (COLLINGTON; PARKER; ARMSTRONG, 1990; EYNG et al., 2014; NIEWOLD, 2006; OETTING et al., 2006).

A restrição ao uso de antimicrobianos como melhoradores de desempenho se deve ao fato de essas substâncias, em doses subterapêuticas, poderem selecionar bactérias resistentes ou induzirem mutações, favorecendo o desenvolvimento de resistência bacteriana cruzada, além de possibilitar a presença de resíduos na carcaça dos animais de produção destinados ao consumo humano (BEDFORD, 2000; DANESHMAND et al., 2005; JAHANBAKHSH et al., 2015; JOHNSTON, 2001; KELLEY et al., 1998; MELLOR, 2000; ROE; PILLAI, 2003; SALEHA et al., 2009; SIMON, 2005; SMITH, 1975; WEGENER, 2003; ZEYNER; BOLDT, 
2006). Por essas razões, é crescente a demanda por produtos alternativos que sejam capazes de substituir eficientemente os antimicrobianos, mantendo os índices de produtividade condizentes e garantindo a qualidade e segurança dos produtos finais (ALLAN; BULKEI, 2005; COLLINGTON; PARKER; ARMSTRONG, 1990; EYNG et al., 2014; HUGUET et al., 2006; JUKNA; JUKNA; ŠIMKUS, 2005; LODDI et al., 2000; NIEWOLD, 2006). Dentre as alternativas mais pesquisadas destacam-se probióticos, prebióticos, ácidos orgânicos e extratos vegetais (OETTING et al., 2006).

Os probióticos constituem-se de microrganismos vivos que são capazes de colonizar o trato gastrintestinal do animal, auxiliando no estabelecimento e manutenção da sua microbiota intestinal, propiciando, dessa forma, a colonização por microrganismos benéficos, que irão competir por espaço e nutrientes com os microrganismos indesejáveis (patogênicos). Também possuem a capacidade de promover a produção de enzimas digestivas e vitaminas do complexo B e estimular a imunidade da mucosa intestinal, promovendo proteção contra toxinas produzidas por outros microrganismos (CAMPOS et al., 2014; FULLER, 1989; LIMA et al., 2003; LODDI et al., 2000).

Outro produto que tem despertado o interesse da comunidade científica é a própolis, produto proveniente da atividade apícola, devido à sua diversidade de propriedades funcionais, tais como antibacteriana, antiviral, anti-infecciosa, anti-inflamatória, antifúngica, antitumoral, imunoestimulante e antioxidante (AL-WAILI et al., 2012; BÚFALO et al., 2009a,b; COLONI et al., 2007; DUARTE et al., 2014; EYNG et al., 2014; FREITAS et al., 2006; FUNARI; FERRO, 2006; GEKKER et al., 2005; GHISALBERTI, 1979; MARCUCCI et al., 2001; ORSI et al., 2000; ORSI et al., 2005a,b; ORSI et al., 2006; SFORCIN et al., 2000; SFORCIN et al., 2001; VARGAS et al., 2004). Por todas estas propriedades, a própolis tem sido utilizada frequentemente na medicina humana alternativa (COLONI et al., 2007; GHISALBERTI, 1979; MOT; TÎRZIU; NICHITA, 2014; SFORCIN; BANKOVA, 2011).

Mais de 300 compostos químicos foram isolados da própolis, sendo os flavonoides o grupo ao qual se atribui a maioria das propriedades funcionais de interesse. Também, são encontrados aldeídos aromáticos, ácidos fenólicos, ácidos orgânicos, minerais, vitaminas e aminoácidos (ALENCAR et al., 2007; BEYRAGHDAR KASHKOOLI et al., 2011; CASTRO et al., 2007; EYNG et al., 2014; LUSTOSA et al., 2008; NAKAMURA et al., 2010; OLDONI, 2007). A própolis demonstra eficiente atividade bacteriostática e bactericida em relação a diversos gêneros de bactérias gram positivas e gram negativas (AL-WAILI et al., 2012; KORU et al., 2007; ORSI et al., 2005a,b; TORRES et al., 2000). 
A utilização da própolis em dietas animais tem demonstrado efeitos positivos sobre o desempenho de suínos, frangos de corte, coelhos, vacas leiteiras, caprinos e peixes (BIAVATTI et al., 2003; ÇETIN et al., 2010; DANESHMAND et al., 2015; DENLI et al., 2005; EYNG et al., 2014; FRANCO et al., 2007; FREITAS et al., 2011; GARCIA et al., 2004; KAČÁNIOVÁ et al., 2012; LANA et al., 2005; MERESTA et al., 1989; SANCHEZ; GALARDI, 1988; SHALMANY; SHIVAZAD, 2006; TALAS et al., 2014; TATLI SEVEN et al., 2008; TEKELI et al., 2011). Dessa forma, a própolis apresenta-se como uma alternativa não-convencional para controlar processos infecciosos. No entanto, estudos sobre os benefícios da própolis ainda são escassos, principalmente como substituto aos antimicrobianos na suinocultura (COELHO et al., 2010). 


\section{HIPÓTESE}

Considerando as propriedades bacteriostática e bactericida da própolis, a hipótese do experimento é que a combinação de própolis bruta e probiótico seja capaz de eliminar microrganismos indesejáveis (patogênicos) e, assim, possibilitar a colonização do trato gastrintestinal por bactérias benéficas, melhorando, dessa forma, o desempenho animal. 


\section{OBJETIVO}

O objetivo deste experimento foi avaliar os efeitos independentes e da combinação da própolis bruta e do probiótico, adicionados em dietas para leitões recém-desmamados, sobre o desempenho zootécnico, a frequência de diarreia, a digestibilidade dos nutrientes e energia da dieta, a morfometria e peso de órgãos (digestórios e baço), a histologia do epitélio intestinal e a microbiologia do conteúdo intestinal, em comparação ao uso de um antimicrobiano melhorador de desempenho (clorohidroxiquinolina). 


\section{REVISÃO BIBLIOGRÁFICA}

\subsection{Particularidades da fase pós-desmame}

Na produção intensiva de suínos, o desmame é um evento estressante associado com a transição e desarranjo das funções protetoras intestinais, aumento da susceptibilidade a doenças e anorexia, causando significativas perdas econômicas (LALLÈS et al., 2007). O desmame também causa diminuição da altura das vilosidades intestinais que resulta no comprometimento da absorção dos nutrientes (BOUDRY et al., 2004).

No período pós-desmame, a relação entre a microbiota normal do intestino e o hospedeiro é delicada. Os inúmeros fatores que afetam adversamente o leitão neste período, favorecem o desequilíbrio entre as bactérias benéficas e as patogênicas, resultando no aparecimento de distúrbios veiculados pelos componentes desta microbiota (MADEC; JOSSE; CHANTAL, 1982; TANNOCK, 1997). Assim, é possível afirmar que, dos vários gêneros de bactérias do trato gastrintestinal, existem aqueles efetivamente patogênicos e aqueles representados por bactérias que ocasionalmente podem desenvolver quadros de diarreia (SILVA et al., 2007).

A diarreia pós-desmame pode ser causada, principalmente, pela colonização da superfície epitelial por patógenos como a Escherichia coli enteroxigênica, a Salmonella typhimurium e o Clostidium ssp. (OETTING et al., 2006; STEWART; CHESSON, 1993), e pela presença de resíduos alimentares não digeridos e não absorvidos, que servem como substratos para os microrganismos patogênicos. Os resíduos alimentares, juntamente com íons minerais (sódio, potássio e cloro) presentes no epitélio intestinal, contribuem para o aumento da osmolaridade do conteúdo intestinal, dificultando o processo de reabsorção de água e desencadeando a diarreia (BHANDARI et al., 2010; NABUURS et al., 1993, OETTING et al., 2006).

\subsubsection{Microbiota}

As interações entre dieta, microbiota e trato gastrintestinal em mamíferos são extremamente complexas. Um correto equilíbrio da microbiota do trato gastrintestinal promove uma digestão eficiente e máxima absorção de nutrientes, melhorando a resistência às doenças infecciosas (DE ANGELIS et al., 2006). Alterações na rotina e dieta causam estresse no estabelecimento dessas interações e afetam a ecofisiologia gastrintestinal (KONSTANTINOV et al., 2004). Esse é o caso dos leitões no pós-desmame, que são submetidos à alimentação sólida e transporte para outras instalações. Essa combinação de 
fatores estressantes pode levar à ocorrência de diarreia, redução no crescimento e, em alguns casos, à morte.

A população microbiana do trato gastrintestinal possui grande influência na modulação da atividade dos enterócitos e expressão sobre as funções do tecido, resultando em um abrandamento dos efeitos do desmame sobre a função intestinal e, subsequente, crescimento dos leitões (COLLINGTON; PARKER; ARMSTRONG, 1990).

É bem estabelecido que a manipulação da microbiota intestinal tanto em ruminantes como não ruminantes apresenta efeitos significativos sobre a taxa de crescimento e a eficiência na utilização de nutrientes, através de fatores associados com a alteração no equilíbrio de espécies bacterianas no intestino delgado, incluindo alterações na estrutura do intestino delgado, redução na produção de compostos tóxicos como amônia e aminas e redução na utilização de nutrientes essenciais por algumas espécies bacterianas (COLLINGTON; PARKER; ARMSTRONG, 1990).

A manipulação da microbiota no intestino pode ser realizada pelo estabelecimento de um grupo específico de bactérias dentro do trato gastrintestinal pela administração oral de probióticos e compostos naturais (COLLINGTON; PARKER; ARMSTRONG, 1990; DENLI et al., 2005; EYNG et al., 2013; GIANG et al., 2010; JAMROZ et al., 2006; KAČÁNIOVÁ et al., 2012; METZLER; BAUER; MONSENTH, 2005; SHAHRYAR et al., 2011; VEIZAJDELIA et al., 2010; ZHANG; LEE; KIM, 2014).

Informações sobre a microbiota gastrintestinal de suínos ainda é restrita a alguns segmentos do trato gastrintestinal, assim como, os efeitos dos componentes da dieta, terapêuticos e desmame sobre a constituição dessa microbiota (FRANKLIN et al., 2002). Entretanto, é de conhecimento que o trato gastrintestinal de leitões é densamente habitado por bactérias que aumentam de 7-9 (log UFC/g) no estômago, para 9 ( $\log$ UFC/g) no intestino delgado e para 10-11 (log UFC/g) no cólon. Os gêneros característicos encontrados são Lactobacillus, Streptococcus, Peptococcus, Eubacterium, Clostridium, Bifidobacterium e Bacteroides. Dentre todos esses gêneros, os Lactobacillus são de particular interesse por estarem envolvidos na melhoria da função intestinal e saúde animal (DE ANGELIS et al., 2006). 


\subsection{Aditivos em dietas de leitões}

\subsubsection{Antimicrobianos}

A cadeia produtiva de suínos se beneficia com a utilização de antimicrobianos adicionados, em doses subterapêuticas, às dietas animais com o intuito de promover melhores índices de desempenho (COLLINGTON; PARKER; ARMSTRONG, 1990; EYNG et al., 2014; NIEWOLD, 2007). A inclusão tem como objetivo prevenir ou reduzir a incidência de microrganismos patogênicos no trato gastrintestinal e, consequentemente, melhorar a saúde e o crescimento animal (COLLINGTON; PARKER; ARMSTRONG, 1990; FEDALTO et al., 2002; MUHL; LIEBERT, 2007).

Os antimicrobianos melhoradores de desempenho são responsáveis por promover alterações na composição da microbiota intestinal. Essas alterações incluem perda da eficiência de fixação de certos microrganismos ao epitélio intestinal, modificação no perfil e na quantidade de substâncias produzidas no lúmen intestinal e controle de bactérias causadoras de doenças subclínicas que reduzem o crescimento do animal (DIBNER; RICHARDS, 2005; GASKINS et al., 2002; MENTEN, 2002; OETTING et al., 2006; PAGE, 2006).

A administração dos aditivos antimicrobianos em níveis subterapêuticos foi proibida na Europa pelo surgimento de preocupações relacionadas ao desenvolvimento de resistência bacteriana aos antibióticos, a queda na sua eficiência, a permanência de resíduos não degradáveis nos alimentos, a transmissão de cepas bacterianas ao homem através do consumo de carne e derivados, as reações alérgicas em pessoas previamente sensibilizadas e toxicidade (DANESHMAND et al., 2015; JAHANBAKHSH et al., 2015; JOHNSTON, 2001; ROE; PILLAI, 2003; SALEHA et al., 2009; SIMON, 2005; SMITH, 1975; WEGENER, 2003; ZEYNER; BOLDT, 2006).

A possibilidade de resistência bacteriana e a exigência por parte dos consumidores por produtos saudáveis, que não trazem riscos à saúde, induziram a procura por aditivos alternativos, que consistem principalmente de produtos naturais com importantes funções terapêuticas capazes de substituir os antimicrobianos (COLLINGTON; PARKER; ARMSTRONG, 1990; EYNG et al., 2014; NIEWOLD, 2007). 


\subsubsection{Probióticos}

Os probióticos são definidos como microrganismos vivos que quando administrados em quantidades adequadas conferem benefícios à saúde do hospedeiro. Abrangem uma grande variedade de microrganismos vivos que conferem efeitos positivos à microbiota intestinal e à produção de substâncias que proporcionam diversos benefícios ao animal (BERNARDEAU; VERNOUX, 2013; CAMPOS et al., 2014; FULLER, 1989).

O uso de probióticos na alimentação animal é indicado por reduzir a morbidade e mortalidade resultantes da colonização intestinal por microrganismos patogênicos, melhorar o desempenho e as características de produção (CAMPOS et al., 2014; FULLER, 1989). Por serem compostos naturais, os probióticos não causam resistência às drogas ou resíduos prejudiciais nos produtos finais (FULLER, 1989; KYRIAKIS et al., 1999; RASTALL, 2004; SCHAREK et al., 2005).

O principal modo de ação é a exclusão competitiva, exigindo, todavia, a necessidade da administração continuada e de elevadas doses para manifestar seus efeitos. Os probióticos podem também afetar patógenos através da síntese de bacteriocinas, ácidos orgânicos voláteis e peróxido de hidrogênio ou atuar sobre o metabolismo celular, reduzindo a concentração de amônia no organismo e produzindo enzimas como a lactase (DE VRESE et al., 2001; JIN; MARQUARDT; BAIDOO, 2000; KOZASA, 1986; NAIDU; BIDLACK; CLEMENS, 1999; NG et al., 2009; OGAWA et al., 2001).

O mecanismo de ação por exclusão competitiva não está bem elucidado, mas algumas formas de atuação destes microrganismos são a competição por nutrientes, competição física, produção de ácidos, secreção de bacteriocinas, imunidade cruzada, desintoxicação causada por endotoxinas, produção de enzimas digestivas, síntese de vitaminas do complexo B e interações com os sais biliares (FEDALTO et al., 2002; ISOLAURI; SALMINEN; OUWEHAND, 2004; JIN et al., 1997). Dessa maneira, possibilitam menor incidência de microrganismos patogênicos e, consequentemente, influenciam na microbiota, integridade do epitélio intestinal e maturação apropriada do intestino (METZLER; BAUER; MONSENTH, 2006).

O modo de ação dos probióticos sobre os parâmetros morfológicos é influenciado, indiretamente, pela alteração no padrão de fermentação microbiana no trato gastrintestinal (DOMENEGHINI et al., 2006). Portanto, os ácidos graxos de cadeia curta como o ácido acético e butírico, produzidos pelos microrganismos no intestino, podem ter um efeito trófico sobre enterócitos e colonócitos, alterando a taxa de renovação da mucosa intestinal. Dessa 
forma, podem alterar a estrutura das vilosidades e criptas, assim como barreiras de defesa não imunológicas, como o número de células caliciformes e, consequentemente, a camada de muco no trato gastrintestinal (DOMENEGHINI et al., 2006; MAIR et al., 2010).

A identificação de cepas probióticas está relacionada à capacidade de sobrevivência e permanência no hospedeiro, adesão às células epiteliais e produção de ácido lático (BORCHERS et al., 2009; COLLADO et al., 2009; DE ANGELIS et al., 2006). Também, é importante considerar a especificidade do hospedeiro pela bactéria probiótica como um critério de seleção (BERNARDEAU et al., 2008; DE ANGELIS et al., 2006).

As bactérias dos gêneros Lactobacillus e Bifidobacterium são residentes naturais da microbiota do trato gastrintestinal da maioria dos animais e por serem capazes de resistir ao meio gastrintestinal e produzir substâncias antimicrobianas, podem ser selecionadas como cepas constituintes de probióticos (CHANG et al., 2001; ROSS et al., 2010; SIMPSON et al., 2004).

Probióticos com cepas de Lactobacillus conferem benefícios à saúde de leitões por modular suas funções imunes (WALSH et al., 2008; WANG et al., 2009). Esses benefícios à saúde são, em parte, dependentes da persistência da colonização dos Lactobacillus na mucosa intestinal (OUWEHAND; SALMINEN; ISOLAURI, 2002).

A inclusão de probióticos à base de Lactobacillus e Enterococcus em dietas para leitões desmamados se mostrou benéfica, aumentando o consumo diário de ração e, consequentemente, o ganho diário de peso, assim como a digestibilidade dos nutrientes da dieta. Esses probióticos também possuem a capacidade de promover melhora da microbiota intestinal através da maior contagem de bactérias do gênero Lactobacillus (GIANG et al., 2010; VEIZAJ-DELIA et al., 2010; ZHANG; LEE; KIM, 2014).

\subsubsection{Própolis}

A própolis é uma mistura complexa de substâncias resinosas, gomosas e balsâmicas coletadas pelas abelhas melífereas de brotos, flores e exsudados de plantas, as quais são transportadas até a colmeia, sendo sua composição modificada pelo acréscimo de secreções salivares, cera e pólen para obtenção do produto final (SALATINO et al., 2011).

O nome "própolis" é derivado do grego "pro", em defesa de, e "polis", a cidade, e quer dizer "em defesa da cidade ou da colmeia". De fato, as abelhas usam esta substância na entrada da colmeia com a finalidade de fechar as frestas, reduzindo a entrada de vento, insetos e microrganismos, além de ser utilizada para embalsamar pequenos animais mortos que não puderam ser retirados da colmeia (INOUE et al., 2007). É também utilizada como material de 
construção no interior da colmeia para soldar favos, quadros e envernizar o interior dos alvéolos, criando um ambiente asséptico, para que a abelha rainha faça postura (MARCUCCI, 1996).

Em geral, a própolis é composta de 50\% de resina e bálsamo, 30\% de cera, 10\% de óleos essenciais e aromáticos, 5\% de pólen e 5\% de outras substâncias (BURDOCK, 1998). Devido a grande complexidade química, a própolis é considerada uma das misturas mais heterogêneas encontradas em fontes naturais. Já foram identificados e/ou caracterizados mais de 300 constituintes químicos, sendo os principais constituintes os compostos fenólicos, representados pelos flavonoides, ácidos fenólicos e seus ésteres, compostos aos quais são atribuídas suas atividades biológicas (ALENCAR et al., 2007; BEYRAGHDAR KASHKOOLI et al., 2011; CASTRO et al., 2007; EYNG et al., 2014; LUSTOSA et al., 2008; NAKAMURA et al., 2010; OLDONI, 2007).

Dentre os compostos fenólicos presentes na própolis, destacam-se os flavonoides e os ácidos fenólicos. A ingestão de flavonoides auxilia diversos processos fisiológicos, contribui na absorção e ação de vitaminas, atua nos processos de cicatrização como antioxidante, além de apresentarem atividade antimicrobiana (MENEZES, 2005).

A composição química da própolis é variável e dependente dos locais de coleta, por isso, apresenta diferenças na proporção dos seus compostos e, consequentemente, influencia o tipo de ação farmacológica e toxicológica de uma amostra (BURDOCK, 1998; CASTRO et al., 2007; OLIVEIRA et al., 2012).

Estudos comparativos revelaram que independentemente das diferenças na composição química, a própolis sempre demonstra considerável atividade biológica seja em menor ou maior grau, uma vez que seu efeito bactericida e fungicida é indispensável para preservar a vida na colmeia (KUJUMGIEV et al., 1999; SEIDEL et al., 2008). Assim, a diversidade química da própolis pode fornecer informações importantes (BANKOVA, 2009).

Ainda que amplamente utilizada na medicina popular, por muito tempo a própolis foi considerada um subproduto das abelhas. Entretanto, o interesse de pesquisadores de todo o mundo se voltou para as suas inúmeras propriedades terapêuticas. Em extratos etanólicos, hidroalcoólicos e aquosos e mesmo em sua forma bruta, a própolis tem sido analisada e utilizada para diversas finalidades como agente bactericida, antiviral, fungicida, antiinflamatório, antiparasitário, imunoestimulante, antioxidante, cicatrizante, anestésico e anticancerígeno (AL-WAILI et al., 2012; BÚFALO et al., 2009a,b; FREITAS et al., 2006; FUNARI; FERRO, 2006; GEKKER et al., 2005; GHISALBERTI, 1979; MARCUCCI et al., 
2001; ORSI et al., 2000; ORSI et al., 2005a,b; ORSI et al., 2006; SFORCIN et al., 2000; SFORCIN et al., 2001; VARGAS et al., 2004).

A ação bacteriostática e bactericida in vitro dos extratos de própolis foi testada em diferentes linhagens de bactérias (AL-WAILI et al., 2012; KORU et al., 2007; ORSI et al., 2005a,b; TORRES et al., 2000). Essa atividade possui correlação positiva com a quantidade de compostos fenólicos e flavonoides (ALENCAR et al., 2007; NEDJI; LOUCIF-AYAD, 2014).

Mesmo considerando os flavonoides como responsáveis pelas propriedades terapêuticas da própolis, sendo sua presença utilizada como índice para qualificar os produtos (WILLIAMS; SPENCER; RICE-EVANS, 2004), demonstrou-se que o potencial biológico se deve também ao sinergismo de todos os seus constituintes (MARCUCCI, 1996).

A atividade antibacteriana da própolis foi testada em diversas bactérias gram-positivas e gram-negativas, sendo constatada maior ação sobre as gram-positivas (BIANCHINI; BEDENDO, 1998; COELHO et al., 2010). A menor sensibilidade das gram-negativas deve-se provavelmente às diferenças na constituição química da parede celular destas bactérias, conferindo maior complexidade química em comparação a das bactérias gram-positivas (MARCUCCI et al., 2001; MENEZES, 2005; MOT; TÎRZIU; NICHITA, 2014; NEDJI; LOUCIF-AYAD, 2014; PINTO et al., 2001; SILVA et al., 2006; VARGAS et al., 2004; WOJTYCZKA et al., 2013).

A própolis preserva a eficácia da sua ação antimicrobiana, ao contrário do que ocorre com os antibióticos sintéticos, aos quais as bactérias desenvolvem resistência gradualmente, sendo necessária a introdução periódica de novos produtos. A eficácia antimicrobiana é conferida pela variabilidade da própolis, em razão de ser um produto que tem origem da disponibilidade de recursos florais encontrados pelas abelhas (MOT; TÎRZIU; NICHITA, 2014).

Pesquisas indicam que quando avaliada a atividade antibacteriana da própolis sobre espécies bacterianas responsáveis por causar infecções graves em animais de produção, não há o desenvolvimento de resistência bacteriana à própolis. Esses resultados demonstram a possibilidade de incluir a própolis como um tratamento alternativo, evitando o desenvolvimento de resistência de cepas bacterianas (MOT; TÎRZIU; NICHITA, 2014).

Em frangos de corte, a própolis, na forma bruta e extrato etanólico, promoveu melhora na saúde intestinal por controlar o crescimento de microrganismos patogênicos no trato gastrintestinal e, consequentemente, melhorou as funções digestivas e absortivas. As vantagens adicionais da utilização da própolis em dietas para frangos de corte derivam da 
melhora no sistema imune e no desempenho de frangos de corte, além da ausência de resíduos na carcaça que podem comprometer a saúde humana (ÇETIN et al., 2010; DANESHMAND et al., 2015; DENLI et al., 2005; EYNG et al., 2014; FREITAS et al., 2011; KAČÁNIOVÁ et al., 2012; SHALMANY; SHIVAZAD, 2006; TATLI SEVEN et al., 2008; TEKELI; KUTLU; CELIK, 2011).

Em carpas, a própolis foi capaz de minimizar o dano tecidual causado pelo arsênio, representando uma alternativa para proteger tecidos e órgãos contra as doenças degenerativas causadas pelo acúmulo de arsênio (TALAS et al., 2014). 


\section{MATERIAL E MÉTODOS}

O experimento foi realizado na creche experimental do Setor de Suinocultura do Departamento de Zootecnia da Escola Superior de Agricultura "Luiz de Queiroz" (ESALQ), Universidade de São Paulo (USP), Piracicaba - SP, no período de novembro de 2014 a janeiro de 2015. Os procedimentos experimentais foram submetidos à avaliação da Comissão de Ética no Uso de Animais (CEUA), sendo aprovados sob o número de protocolo 2014-36.

\subsection{Instalações}

A sala de creche experimental possui sua construção em alvenaria e área de $102,50 \mathrm{~m}^{2}$ $(12,50 \times 8,20 \mathrm{~m})$, pé direito de 2,85 m, telhado de cerâmica e paredes com aberturas laterais para renovação de ar, sendo providas de um sistema de cortinas para controle da temperatura.

A sala de creche é equipada com 20 baias metálicas suspensas, dispostas em quatro fileiras de cinco baias. Cada baia possui área de $1,80 \mathrm{~m}^{2}(1,20 \times 1,50 \mathrm{~m})$, sendo provida de comedouro semi-automático e bebedouro tipo chupeta, assim como sistema de aquecimento proporcionado por lâmpada infravermelha de $250 \mathrm{~W}$. A área abaixo do bebedouro é constituída de piso metálico vazado, enquanto que o restante é de concreto compacto, correspondente à área adjacente ao comedouro.

\subsection{Teste de aceitabilidade}

Para estimar o consumo de ração com inclusão de própolis bruta foi realizado teste de aceitabilidade na creche experimental do Setor de Suinocultura do Departamento de Zootecnia da Escola Superior de Agricultura "Luiz de Queiroz" (ESALQ), Universidade de São Paulo (USP), Piracicaba - SP, em novembro de 2014 no período de sete dias.

Foram utilizados 30 leitões recém-desmamados, machos castrados e fêmeas, com aproximadamente $6,0 \mathrm{~kg}$ de peso vivo e 21 dias de idade, provenientes das ninhadas do próprio Setor de Suinocultura.

O teste preliminar obedeceu a um delineamento em blocos causalizados (definidos pelo peso inicial, sexo e ninhada) com cinco tratamentos, três repetições (blocos) por tratamento e dois animais por unidade experimental (baia), um macho castrado e uma fêmea.

Os tratamentos consistiram de um tratamento controle (dieta basal sem adição da própolis bruta) e quatro tratamentos com inclusão de níveis crescentes de própolis bruta $(0,1 \%, 0,2 \%, 0,3 \%$ e $0,4 \%)$. A dieta basal foi formulada de acordo com as recomendações nutricionais para leitões na fase de creche (NATIONAL RESEARCH COUNCIL - NRC, 
2012) e corresponde à dieta pré-inicial II do experimento. A composição da dieta é apresentada na Tabela 1 .

Tabela 1 - Composição das dietas basais

\begin{tabular}{|c|c|c|c|}
\hline Item & Pré-inicial I & Pré-inicial II & Inicial \\
\hline \multicolumn{4}{|l|}{ Ingredientes, $\%$} \\
\hline Milho & 49,69 & 57,08 & 63,41 \\
\hline Farelo de soja, $46 \%$ & 25,00 & 25,00 & 28,55 \\
\hline Soro de leite desidratado & 13,52 & 6,76 & - \\
\hline Plasma sanguíneo desidratado & 5,00 & 2,50 & 0,50 \\
\hline Açúcar & 2,50 & 4,00 & 4,00 \\
\hline Óleo de soja & 0,52 & 0,62 & - \\
\hline Fosfato bicálcico & 1,09 & 1,20 & 1,07 \\
\hline Calcário calcítico & 1,04 & 0,94 & 0,84 \\
\hline Sal & 0,26 & 0,46 & 0,58 \\
\hline Óxido de zinco & 0,30 & 0,25 & - \\
\hline L-Lisina. $\mathrm{HCl}, 78 \%$ & 0,46 & 0,51 & 0,45 \\
\hline DL-Metionina, 99\% & 0,19 & 0,19 & 0,15 \\
\hline L-Treonina, 98,5\% & 0,13 & 0,16 & 0,14 \\
\hline L-Valina, $96,5 \%$ & 0,04 & 0,07 & 0,03 \\
\hline Premix mineral $^{1}$ & 0,10 & 0,10 & 0,10 \\
\hline Premix vitamínico $^{2}$ & 0,15 & 0,15 & 0,15 \\
\hline Antioxidante & 0,02 & 0,02 & 0,02 \\
\hline Total & 100,00 & 100,00 & 100,00 \\
\hline \multicolumn{4}{|l|}{ Composição calculada } \\
\hline Energia metabolizável, kcal/kg & 3400 & 3400 & 3350 \\
\hline Proteína bruta, $\%$ & 21,72 & 19,69 & 19,40 \\
\hline Cálcio, \% & 0,85 & 0,80 & 0,70 \\
\hline Fósforo disponível, \% & 0,45 & 0,40 & 0,33 \\
\hline Lactose, $\%$ & 10,00 & 5,00 & - \\
\hline Lisina digestível, $\%$ & 1,50 & 1,35 & 1,23 \\
\hline Metionina digestível, \% & 0,46 & 0,44 & 0,41 \\
\hline Metionina + Cistina digestível, \% & 0,82 & 0,74 & 0,68 \\
\hline Treonina digestível, $\%$ & 0,88 & 0,79 & 0,73 \\
\hline Triptofano digestível, \% & 0,26 & 0,22 & 0,20 \\
\hline Valina digestível, \% & 0,95 & 0,86 & 0,78 \\
\hline Isoleucina digestível, \% & 0,77 & 0,69 & 0,68 \\
\hline
\end{tabular}




\subsection{Animais}

Foram utilizados 120 leitões híbridos comerciais recém-desmamados, machos castrados e fêmeas, com aproximadamente $6,0 \mathrm{~kg}$ de peso vivo e 21 dias de idade, provenientes de uma granja comercial de suínos em sistema de ciclo completo, situada no município de Mogi Mirim - SP.

\section{$5.4 \quad$ Manejo}

Os animais foram transportados em caminhão, equipado com piso antiderrapante e portas de abertura vertical independentes. O transporte dos leitões foi realizado logo pela manhã para evitar calor excessivo durante o trajeto Mogi Mirim - Piracicaba.

No recebimento, os leitões foram separados em machos e fêmeas e pesados individualmente, o que correspondeu à pesagem do primeiro dia do experimento. A primeira pesagem foi utilizada para o alojamento dos animais de acordo com o delineamento estabelecido em função do peso inicial e sexo.

As pesagens foram realizadas no $1^{\circ}, 7^{\circ}, 21^{\circ}$ e $35^{\circ}$ dia do experimento, para o cálculo do ganho diário de peso e conversão alimentar. As rações e a água foram fornecidas à vontade durante todo o período experimental de 35 dias. $\mathrm{O}$ funcionamento dos bebedouros foi verificado diariamente. As rações foram armazenadas em baldes plásticos de 65 litros dispostos na frente de cada baia, correspondendo ao tratamento específico. As sobras e os desperdícios de ração de cada baia foram anotados para a determinação do consumo diário de ração e conversão alimentar.

A limpeza da sala de creche foi realizada diariamente pela manhã, utilizando-se mangueira de água pressurizada para a limpeza dos corredores e da parte abaixo das baias.

\subsection{Delineamento experimental}

O experimento seguiu um delineamento em blocos completos casualizados (definidos pelo peso inicial e sexo) com cinco tratamentos, oito repetições (blocos) por tratamento e três animais por unidade experimental (baia), um macho castrado e duas fêmeas.

\subsection{Tratamentos}

Os tratamentos consistiram de combinações de 2 níveis de própolis bruta (com e sem adição), 2 níveis de probiótico (com e sem adição) e um tratamento adicional (antimicrobiano) com halquinol $60 \%$, obedecendo a um esquema fatorial $2 \times 2+1$, conforme descrito a seguir: 
- Controle: dieta basal sem a adição de qualquer aditivo;

- Própolis (P): dieta basal com inclusão de $0,4 \%$ de própolis bruta (definido no teste de aceitabilidade);

- Probiótico (PRO): dieta basal com inclusão de $0,1 \%$ de probiótico à base de Lactobacillus $\left(3,5 \times 10^{11} \mathrm{UFC} / \mathrm{kg}\right.$ de Lactobacillus acidophillus e $3,5 \times 10^{11} \mathrm{UFC} / \mathrm{kg}$ de Enterococcus faecium);

- Própolis + probiótico (P+PRO): dieta basal com inclusão de $0,4 \%$ de própolis bruta e de $0,1 \%$ de probiótico à base de Lactobacillus $\left(3,5 \times 10^{11} \mathrm{UFC} / \mathrm{kg}\right.$ de Lactobacillus acidophillus e 3,5 x $10^{11} \mathrm{UFC} / \mathrm{kg}$ de Enterococcus faecium,);

- Antimicrobiano: dieta basal com inclusão de 120 ppm do princípio ativo do antimicrobiano melhorador de desempenho (clorohidroxiquinolina).

\subsubsection{Própolis}

A própolis foi fornecida pela Cooperativa Nacional de Apicultores (CONAP), sendo proveniente da região de Minas Gerais.

Como foi adquirida na forma bruta (lascas) foi necessário moer a própolis para ser adicionada, da forma mais homogênea possível, nas dietas para leitões recém-desmamados. Para a moagem da própolis foi utilizado multiprocessador, sendo necessário manter a própolis em congelador por 12 horas para que essa se encontrasse o menos maleável possível no momento da trituração. Após a moagem, a própolis triturada foi acondicionada em sacos plásticos de aproximadamente $200 \mathrm{~g}$ e armazenados em congelador até sua inclusão nas dietas experimentais. Essa precaução foi adotada para evitar compactação da própolis.

Por meio do teste de aceitabilidade prévio foi definida a utilização da própolis bruta na concentração de $0,4 \%$ nas dietas experimentais determinadas como P e P+PRO.

\subsubsection{Probiótico}

O probiótico foi fornecido pela empresa IMEVE localiza em Jaboticabal - SP. O produto utilizado foi o DBI Probiótico - Pó para suíno que possui níveis de garantia de 3,5 x $10^{11} \mathrm{UFC} / \mathrm{kg}$ de Lactobacillus acidophillus e $3,5 \times 10^{11} \mathrm{UFC} / \mathrm{kg}$ de Enterococcus faecium, o veículo utilizado pela empresa foi o leite em pó integral. De acordo com a especificação da empresa foi incluído um quilo do produto por tonelada de ração nas deitas experimentais determinadas como PRO e P+PRO. 


\subsubsection{Halquinol}

O antimicrobiano melhorador de desempenho utilizado foi o halquinol $60 \%$. Com inclusão de 120 ppm do principio ativo (clorohidroxiquinolina) na dieta experimental determinada como antimicrobiano. Essa dieta representou o tratamento controle positivo do experimento.

\subsection{Dietas}

As dietas foram confeccionadas na Fábrica de Ração do Departamento de Zootecnia da Escola Superior de Agricultura "Luiz de Queiroz" (ESALQ), Universidade de São Paulo (USP), Piracicaba - SP.

As dietas isonutritivas foram formuladas de acordo com as recomendações para leitões na fase de creche (NRC, 2012). Foi utilizado um programa nutricional de três fases: Préinicial I (1 a 7 dias), Pré-inicial II (7 a 21 dias) e Inicial (21 a 35 dias). A adição dos aditivos foi realizada na forma “on top", sendo utilizada apenas uma mesma formulação acrescida dos aditivos (Tabela 1).

\subsection{Caracterização da própolis}

\subsubsection{Preparo do extrato etanólico de própolis}

O extrato etanólico de própolis foi preparado em tubo falcon, utilizando-se 2 gramas de própolis bruta triturada adicionados a $25 \mathrm{~mL}$ de etanol $80 \%(\mathrm{v} / \mathrm{v})$. A extração foi feita $70{ }^{\circ} \mathrm{C}$, em banho de água termostatizado, por 30 minutos, sob agitação constante. Em seguida realizou-se a filtração em papel de filtro e o extrato etonólico de própolis foi transferido para um frasco de vidro âmbar com tampa de rosca. O extrato etanólico de própolis foi armazenado sob-refrigeração.

\subsubsection{Determinação do teor de compostos fenólicos totais}

A análise do teor de compostos fenólicos totais do extrato etanólico de própolis foi realizada de acordo com o método espectrofotométrico de Folin-Ciocalteau, descrito por Singleton, Orthofer e Lamuela-Raventós (1999), utilizando ácido gálico como padrão. O reagente de Folin-Ciocalteau é uma solução complexa de íons poliméricos formados a partir de heteropoliácidos fosfomolibídicos e fosfotungísticos. Esse reagente oxida os fenolatos, reduzindo os ácidos a um complexo azul Mo-W. 
O extrato etanólico de própolis foi diluído na proporção de 1:100 e 1:200, sendo uma alíquota de $0,5 \mathrm{~mL}$ da amostra diluída transferida para um tubo com tampa de rosca e adicionado 2,5 mL do reagente Folin-Ciocalteau diluído em água na proporção de 1:10. A mistura permaneceu em repouso por um período que variou de 3 a 8 minutos. Em seguida, foram adicionados $2 \mathrm{~mL}$ de carbonato de sódio $4 \%$ e os tubos deixados em repouso por 2 horas, ao abrigo da luz. A absorbância foi medida em espectrofotômetro UV-mini 1240 (Shimadzu Co.) a $740 \mathrm{~nm}$. Uma amostra em branco foi preparada nas mesmas condições e os resultados do teor de compostos fenólicos totais foram expressos como equivalente de ácido gálico (EAG).

\subsubsection{Determinação do teor de flavonoides totais}

A análise do teor de flavonoides totais do extrato etanólico de própolis foi realizada de acordo com o método descrito por Park et al. (1995). O princípio desta reação se baseia na formação de quelatos entre o metal alumínio e os flavonoides, principalmente os flavonóis (3hidroxiflavonas) como, por exemplo, a quercetina, em soluções alcoólicas, levando a um efeito batocrômico do espectro de absorção dos flavonoides, com alteração da coloração (JURD; GUEISSMAN, 1956).

A reação colorimétrica foi realizada pela mistura de $0,5 \mathrm{~mL}$ do extrato etanólico de própolis (1:50 e 1:100), 4,3 mL de etanol $80 \%, 0,1 \mathrm{~mL}$ de cloreto de alumínio $10 \%$ e $0,1 \mathrm{~mL}$ de acetato de potássio $1 \mathrm{M}$. Como controle para as amostras foi utilizado $0,1 \mathrm{~mL}$ de acetato de potássio e 4,9 $\mathrm{mL}$ de etanol $80 \%$. Após 40 minutos de repouso no escuro, a absorbância das amostras foi medida em espectrofotômetro UV-mini 1240 (Shimadzu-Co) a 415nm. Os resultados do teor de flavonoides foram expressos em termos de quercetina, com base em uma curva padrão desse flavonoide.

\subsubsection{Determinação da atividade antioxidante pelo método ABTS+}

O método utilizado para avaliar a atividade antioxidante por meio da captura da radical $\mathrm{ABTS}^{+}$[2,2-azinobis (3-etilbenzotiazolina-6-ácido sulfônico)] foi descrito por Rufino et al. (2007). O radical $\mathrm{ABTS}^{+}$foi formado pela reação do ABTS $(7 \mathrm{mM})$ com persulfato de potássio $(140 \mathrm{mM})$ e incubados a temperatura de $25^{\circ} \mathrm{C}$, no escuro, durante $12-16 \mathrm{~h}$. Uma vez formado, o radical foi diluído com etanol até a obtenção do valor de absorbância de $0,700 \mathrm{~nm}$ $\pm 0,200 \mathrm{~nm}$ a $734 \mathrm{~nm}$. Em ambiente escuro, um volume de 3,0 $\mathrm{mL}$ da solução de radical $\mathrm{ABTS}^{+}$foi acrescentado a $30 \mu \mathrm{L}$ de cada amostra de extrato etanólico de própolis $(1: 1150 \mathrm{e}$ 1:1250) e as absorbâncias lidas em espectrofotômetro a 734 nm, após seis minutos de 
repouso. Como referência, foi utilizado o Trolox, um antioxidante sintético análogo à vitamina $\mathrm{E}$, nas concentrações de $0-15 \mu \mathrm{M}$. Os resultados da atividade antioxidante foram expressos em TEAC (atividade antioxidante equivalente ao Trolox).

\subsubsection{Cromatografia em camada delgada (CCD)}

As análises por cromatografia em camada delgada foram realizadas em cromatofolhas de sílica gel $60 \mathrm{~F}_{254}$ (Merck Co.). Uma alíquota de $10 \mu \mathrm{L}$ do extrato etanólico de própolis na concentração de $2 \mathrm{mg} / \mathrm{mL}$ foi aplicada na placa. O tempo de desenvolvimento dos cromatogramas foi aproximadamente 20 minutos, utilizando-se como fase móvel o sistema de solvente composto por acetato de etila:clorofórmio $(3: 7, \mathrm{v} / \mathrm{v})$. As cromatoplacas foram visualizadas sob luz ultravioleta, no comprimento de onda de $366 \mathrm{~nm}$ (OLDONI, 2007).

\subsection{Análises bromatológicas e energia das dietas e fezes}

A coleta das amostras da dieta (Inicial I) foi realiza retirando uma porção de aproximadamente 100 gramas de cada saco, desconsiderando a porção do primeiro e do último saco, que correspondem ao início e o final da retirada da mistura, totalizando uma amostra de um quilo. As amostras foram armazenadas em sacos plásticos sob-refrigeração.

Foi adotado o método de coleta parcial de fezes (SAKOMURA; ROSTAGNO, 2007), com a inclusão de $0,1 \%$ de óxido de cromo $\left(\mathrm{Cr}_{2} \mathrm{O}_{3}\right)$ às dietas (Inicial I) como indicador de indigestibilidade. O período de fornecimento do indicador foi de 14 dias, correspondente ao fornecimento da ração Inicial $\mathrm{I}$, do $21^{\circ}$ ao $35^{\circ}$ dia de experimentação, sendo sete dias para manutenção do fluxo do indicador pelo trato digestório e sete dias de coleta de fezes.

As amostras de fezes foram coletadas duas vezes ao dia (manhã e tarde) de todos os três animais em cada baia, diretamente do reto dos animais com auxílio de estimulação retal, sendo utilizada uma luva por baia. As amostras de fezes de cada baia totalizaram aproximadamente 600 gramas. Após a coleta, as amostras de fezes foram armazenadas em sacos plásticos em congelador $\left(-18^{\circ} \mathrm{C}\right)$.

Posteriormente, as amostras de ração e fezes foram enviadas ao Laboratório de Bromatologia e Minerais do Instituto de Zootecnia (IZ), Nova Odessa - SP, para serem homogeneizadas e analisadas para matéria seca, proteína bruta, matéria mineral, extrativo não nitrogenado e energia bruta, seguindo os procedimentos descritos por Silva e Queiroz (2006). 


\subsection{Digestibilidade aparente dos nutrientes e energia bruta}

A determinação dos coeficientes de digestibilidade aparente (CDap) da matéria seca, da proteína bruta, da matéria mineral, do extrativo não nitrogenado e da energia bruta foi realizada utilizando a equação proposta por Matterson et al. (1965):

$$
\mathrm{CDap}=100-100 \times\left(\frac{\% \text { marcador na ração }}{\% \text { marcador nas fezes }}\right) \times\left(\frac{\% \text { nutrientes nas fezes }}{\% \text { nutrientes na ração }}\right)
$$

\subsubsection{Determinação do marcador óxido de cromo $\left(\mathrm{Cr}_{2} \mathrm{O}_{3}\right)$}

A técnica utilizada para a determinação da quantidade do marcador óxido de cromo $\left(\mathrm{Cr}_{2} \mathrm{O}_{3}\right)$ nas rações e fezes foi a da fluorescência de raios-X com dispersão por comprimento de onda.

Essa análise foi realizada em espectrofotômetro de dispersão por raio-X SHIMADZU EDX-720 no Laboratório Multiusuário em Produção Vegetal do Departamento de Produção Vegetal (LPV) da Escola Superior de Agricultura “Luiz de Queiroz" (ESALQ), Universidade de São Paulo (USP), Piracicaba - SP, sob a supervisão do Dr. Tiago Tezotto.

\subsection{Frequência de diarreia}

A ocorrência de diarreia foi monitorada diariamente para o cálculo da frequência, considerando a presença (fezes líquidas) ou ausência (fezes normais) de cada animal em cada baia.

\subsection{Morfometria e peso de órgãos}

No $35^{\circ}$ dia de experimentação, um animal por unidade experimental, o qual mais se aproximava do peso médio da baia, foi insensibilizado em corrente elétrica e abatido.

Os órgãos digestórios (estômago, pâncreas, fígado e intestino delgado) e o baço foram pesados para o cálculo do peso absoluto e relativo dos órgãos, o comprimento do intestino delgado também foi mensurado para o cálculo da densidade do intestino. Os pesos do pâncreas, fígado (sem a vesícula biliar), estômago vazio, intestino limpo e baço foram determinados em balança de mesa. O comprimento do intestino delgado foi mensurado com o auxílio de uma fita métrica afixada na borda de uma mesa. 


\subsection{Histologia do epitélio intestinal}

Foram coletadas amostras do duodeno (15 cm da válvula pilórica do estômago), em seguida foram lavadas em solução salina $(0,85 \%$ de $\mathrm{NaCl})$, fixadas em solução de formol tamponado neutro a $10 \%$ e armazenadas até a confecção das lâminas para a mensuração da altura de vilosidade, profundidade de cripta e relação altura de vilosidade:profundidade de cripta.

As lâminas histológicas foram confeccionadas pela HISTOTECH Lâminas Didáticas, São Paulo - SP, sendo coradas pelo método azul de toluidina como descrito por AFIP (1994). As imagens foram registradas utilizando-se um sistema de análise de imagens acoplado ao microscópio óptico. Posteriormente, foram realizadas as mensurações de altura de vilosidade e profundidade de cripta. Para o cálculo da altura de vilosidade e profundidade de cripta foram registradas as mensurações de aproximadamente 15 vilosidades e criptas por lâmina.

O registro das imagens foi realizado em microscópio óptico (10x), utilizando sistema de captura de imagens BELKIN 2000 do Laboratório de Anatomia e Fisiologia Animal do Departamento de Zootecnia da Escola Superior de Agricultura “Luiz de Queiroz" (ESALQ), Universidade de São Paulo (USP), Piracicaba - SP, com o auxilio da Dra. Débora Botéquio Moretti e da graduanda em Engenharia Agronômica, Caroline Batista dos Santos.

\subsection{Microbiologia do conteúdo intestinal}

Amostras do conteúdo intestinal do jejuno e ceco foram coletadas imediatamente após corte do intestino delgado correspondente ao jejuno $(150 \mathrm{~cm}$ da junção ileocecal) e do ceco através de abertura da comissura cecal. As amostras de aproximadamente $5 \mathrm{~g}$ foram coletadas com o auxílio de uma lâmina de vidro desinfetada com álcool $80 \%$ e armazenadas em tubos falcon de $15 \mathrm{~mL}$ estéreis e mantidas em refrigeração até o seu processamento.

Para a realização das culturas microbiológicas, foi necessário pesar $1 \mathrm{~g}$ desse material coletado. Em seguida, as amostras foram submetidas a uma diluição $10^{-1}$, onde $1 \mathrm{~g}$ da amostra foi diluído em $9 \mathrm{~mL}$ de solução salina $0,85 \%$ e homogeneizadas em vortex por $30 \mathrm{~s}$, essa constituiu a amostra mãe utilizada para as próximas diluições. Assim, procederam-se

diluições seriadas até $10^{-7}$, pipetando-se $100 \mu \mathrm{L}$ da diluição anterior em eppendrof com 900 $\mu \mathrm{L}$ de solução salina $0,85 \%$, e homogeneizando em vortex por $10 \mathrm{~s}$. Logo após, uma alíquota de $100 \mu \mathrm{L}$ das diluições $10^{-6}$ e $10^{-7}$ foram semeadas por espalhamento em superfície em cada meio de cultura específico. Por fim, as placas foram incubadas a $37^{\circ} \mathrm{C}$ por 24 horas. 
Após o período de incubação, o número de colônias de cada placa foi contado com o auxílio de uma mesa de luz, utilizando como referência a descrição de coloração das colônias para cada meio de cultura.

As análises microbiológicas foram realizadas no Laboratório de Genética de Microrganismos "Prof. João Lúcio de Azevedo" do Departamento de Genética da Escola Superior de Agricultura "Luiz de Queiroz" (ESALQ), Universidade de São Paulo (USP), Piracicaba - SP, com auxílio da Profa. Dra. Maria Caroline Quecine Verdi e do técnico do laboratório, José Antônio da Silva.

\subsubsection{Contagem bacteriana total}

Utilizou-se ágar Mueller-Hinton para crescimento e determinação da grande maioria dos isolados clínicos como Staphylococcus spp., Enterococcus spp., enterobactérias e Pseudomonas aeruginosa. As colônias de Enterococcus sp. nesse meio apresentaram a coloração branca.

\subsubsection{Contagem de enterobactérias}

Utilizou-se ágar eosina azul de metileno (EMB LEVINE) para isolamento de bactérias entéricas gram-negativas. A eosina Y e o azul de metileno são indicadores. Estes corantes desempenham um papel na diferenciação entre fermentadores de lactose e não fermentadores de lactose, devido à presença ou ausência da absorção do corante nas colônias de bactérias. $\mathrm{O}$ azul de metileno também funciona como um agente seletivo inibindo as bactérias grampositivas para um grau limitado. As colônias de Escherichia coli nesse meio apresentaram a coloração verde metálico brilhante.

\subsubsection{Contagem de lactobacilos}

Utilizou-se o ágar MRS para cultivo e isolamento de Lactobacillus sp. O acetato de sódio, citrato de amônia, magnésio, manganês e tween 80 atuam como fatores de crescimento para lactobacilos. As colônias de Lactobacillus sp. nesse meio apresentaram a coloração branca. 


\subsubsection{Análise dos dados de microbiologia}

Os dados para UFC obtidos foram transformados em $\log _{10}$ e convertido de UFC/100 $\mu \mathrm{L}$ para UFC/mL. Os dados foram analisados pelo procedimento MIXED do SAS $^{\circledR}$ (SAS Institute Inc., Cary, North Carolina, USA).

\subsection{Análise estatística}

Os dados foram submetidos a testes para verificação da adequação ao modelo linear e, posteriormente, à análise de variância utilizando o procedimento MIXED do SAS $^{\circledR}$ (SAS Institute Inc., Cary, North Carolina, USA). Para análise de variância, foram considerados dois modelos matemáticos:

(1) Incluindo os efeitos fixos dos tratamentos, além dos efeitos aleatórios dos blocos e erro experimental, conforme segue:

$Y(i j)=\mu+t(i)+b(j)+\varepsilon(i j)$, onde:

$\mathrm{Y}(\mathrm{ij})=$ variável resposta; $\mu=$ média geral; $\mathrm{t}(\mathrm{i})=$ efeito fixo do $\mathrm{i}$-ésimo tratamento $(\mathrm{i}=$ $1, \ldots 5) ; \mathrm{b}(\mathrm{j})=$ efeito aleatório do j-ésimo bloco $(\mathrm{j}=1, \ldots 8) ; \varepsilon(\mathrm{ij})=$ erro experimental, $\operatorname{NID}\left(0, \sigma^{2}\right)$.

(2) Incluindo apenas os efeitos fixos dos fatores principais própolis e probiótico e suas interações, além dos efeitos aleatórios dos blocos e do erro experimental, conforme segue:

$\mathrm{Y}(\mathrm{ijk})=\mu+\mathrm{p}(\mathrm{i})+1(\mathrm{j})+\mathrm{p}^{*} 1(\mathrm{ij})+\mathrm{b}(\mathrm{k})+\varepsilon(\mathrm{ijk})$, onde:

$\mathrm{Y}(\mathrm{ijk})=$ variável resposta; $\mu=$ média geral; $\mathrm{p}(\mathrm{i})=$ efeito fixo do fator própolis $(\mathrm{i}=$ $1,2) ; 1(j)=$ efeito fixo do fator probiótico $(j=1,2) ; p^{*} 1(i j)=$ efeito fixo da interação entre própolis e probiótico; $\mathrm{b}(\mathrm{k})=$ efeito aleatório do k-ésimo bloco $(\mathrm{k}=1, \ldots 8) ; \varepsilon(\mathrm{ijk})$ $=$ erro experimental, $\operatorname{NID}\left(0, \sigma^{2}\right)$.

O teste utilizado para comparação de médias dos tratamentos foi o teste de Dunnett $(p<0,05)$, onde todos os tratamentos foram comparados com o tratamento antimicrobiano. 


\section{RESULTADOS E DISCUSSÃO}

\subsection{Teste de aceitabilidade}

Pelo teste preliminar, foi possível observar que a inclusão de níveis crescentes de própolis bruta em dietas para leitões recém-desmamados aos 21 dias de idade não influenciou significativamente no consumo diário de ração no período de uma semana (Figura 1). Através desse teste, foi definido o nível de inclusão de própolis bruta em $0,4 \%$ nas dietas experimentais.

Os resultados diferiram dos encontrados por Ito et al. (2009), que constataram que a inclusão de própolis bruta em altas concentrações em dietas para leitões desmamados afeta negativamente a palatabilidade e, consequentemente, promove menor consumo diário de ração. A diferença nos resultados pode ser o fato de os animais utilizados nesse experimento serem desmamados todos aos 21 dias de idade, enquanto que Ito et al. (2009) utilizaram animais desmamados com aproximadamente 24 dias de idades. Provavelmente, os referidos autores, utilizaram animais desmamados com diferentes idades ou, eventualmente, ofereceram uma dieta prévia sem inclusão de própolis, o que pode ter influenciado para a rejeição das dietas experimentais com inclusão de própolis.

Em frangos de corte, também foi constatado menor consumo diário de ração ao incluir própolis tanto na forma bruta quanto na forma de extrato nas dietas (DANESHMAND et al., 2015; DUARTE et al., 2014; EYNG et al., 2014).

Em função de ser um composto balsâmico e, consequentemente, possuir sabor forte e característico, é importante ponderar sua inclusão em dietas animais, principalmente, em dietas para animais que possuem paladar aguçado, como em suínos.

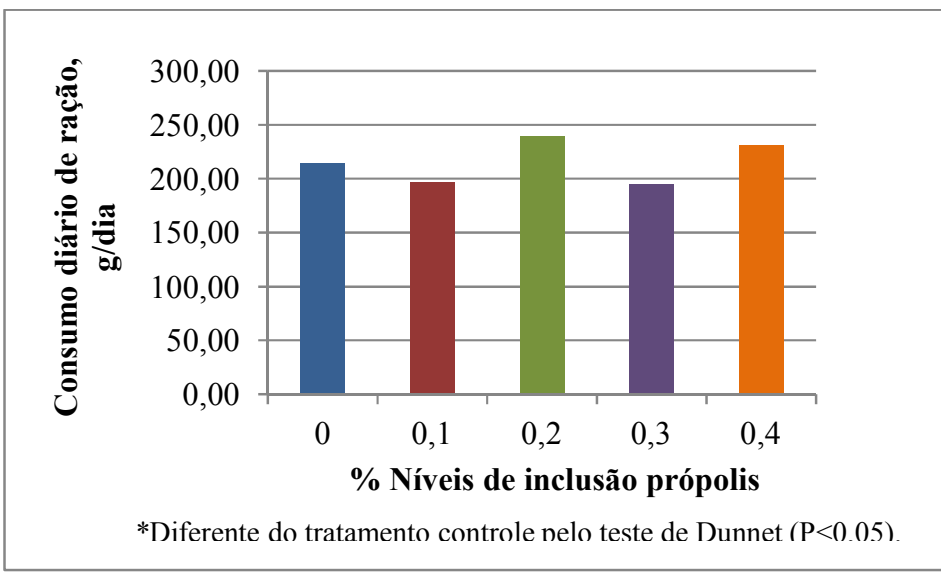

Figura 1 - Consumo diário de ração em diferentes níveis de inclusão de própolis bruta (teste de aceitabilidade) 


\subsection{Caracterização da própolis}

A própolis incluída nas dietas para leitões recém-desmamados foi analisada e enquadrada como própolis verde pertencente ao grupo G12 (própolis verde). A classificação foi comprovada pela análise de cromatografia em camada delgada, comparando-se os extratos das amostras de própolis utilizada no experimento (AM1 e AM2) com outros dois extratos comprovadamente pertencentes ao grupo de classificação G1 (própolis vermelha) e G12 (própolis verde) (Figura 2). A própolis também foi caracterizada em relação à concentração de compostos fenólicos, 130,59 mg GAE/g de extrato; concentração de flavonoides, 0,04 mg quercetina/g de extrato e atividade antioxidante, $2235,15 \mathrm{mg}$ TEAC/g de extrato.

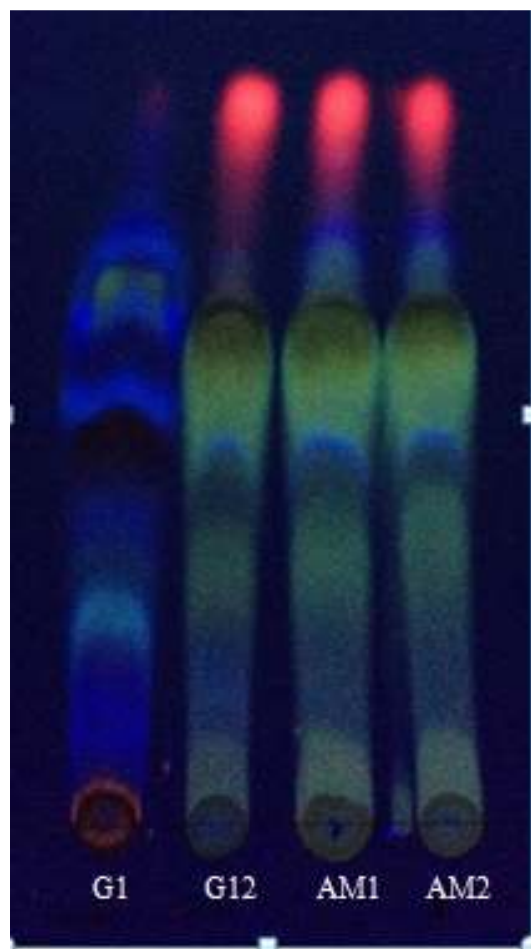

(G1 - própolis vermelha, G12 - própolis verde, AM1 e AM2 - amostras da própolis utilizadas no experimento).

Figura 2 - Bandas cromatográficas dos extratos de própolis 


\subsection{Desempenho}

Os resultados para as variáveis de desempenho dos leitões durante o período de 35 dias de experimentação são apresentados na Tabela 2. Não foi observada diferença significativa $(\mathrm{p}>0,05)$ para os tratamentos sem e/ou com inclusão de própolis e probiótico em comparação ao tratamento antimicrobiano para as variáveis de desempenho de peso vivo, ganho de peso, consumo de ração e conversão alimentar.

Pela observação dos dados é possível perceber uma tendência para menor ganho de peso, no período de 7 a 21 dias de experimentação, ao incluir própolis bruta em dietas para leitões recém-desmamados $(\mathrm{p}<0,10)$, demonstrando que a inclusão de própolis bruta pode afetar negativamente o ganho de peso de leitões nesse período, sem afetar significativamente o consumo de ração no mesmo período. Também é possível verificar uma tendência para melhor conversão alimentar, no período de 21 a 35 dias de experimentação, com a inclusão concomitante de própolis e probiótico nas dietas $(\mathrm{p}<0,10)$, indicando que a inclusão do probiótico minimiza o efeito negativo causado pela própolis sobre a conversão alimentar.

O tratamento com inclusão de antimicrobiano apresentou resultados numericamente superiores para todas as variáveis de desempenho, evidenciando que a inclusão de antimicrobianos em dietas animais é capaz de melhorar o desempenho dos animais (Bosi et al., 2011; Cromwell, 2002; GASKINS; COLLIER; ANDERSON, 2002; NIEWOLD, 2006; NRC, 2012; PAGE, 2006).

A inclusão de própolis bruta em altos níveis é um fator para o menor consumo de ração em leitões desmamados, influenciando negativamente no ganho de peso (ITO et al., 2009). A adição de níveis crescente de própolis também influencia o consumo de ração de frangos de corte, tanto na forma bruta quanto na forma de extrato, com consequente menor ganho de peso, mas não afetando a conversão alimentar (DANESHMAND et al., 2015; DUARTE et al., 2014; EYNG et al., 2014). Daneshmand et al. (2015) observaram pior conversão alimentar em frangos de corte que receberam a combinação de própolis e probiótico à base de Lactobacillus em comparação aos animais que receberam apenas probiótico.

Silva et al. (2007) também não observaram diferença nos parâmetros de desempenho quando incluídos antimicrobianos e probiótico à base de Lactobacillus spp. em diferentes concentrações em dietas para leitões recém-desmamados. Entretanto, Le Bon et al. (2010) constataram que a utilização de probióticos à base de Saccharomyces cerevisiae ssp. e de Pediococcus acidilactici melhoraram a conversão alimentar de leitões desmamados. 







\subsection{Digestibilidade aparente dos nutrientes e energia bruta}

Os resultados para a digestibilidade aparente dos nutrientes (matéria seca, proteína bruta, matéria mineral e extrativo não nitrogenado) e energia bruta, referentes à dieta Inicial I oferecida aos leitões durante o período de experimentação, são apresentados na Tabela 3.

A inclusão de própolis bruta reduziu a digestibilidade do extrativo não nitrogenado em dietas para leitões recém-desmamados $(\mathrm{p}<0,05)$. A inclusão de própolis e probiótico, isolados e em combinação, também influenciou negativamente na digestibilidade de todos os nutrientes, assim como a energia bruta da dieta $(p<0,05)$.

$\mathrm{O}$ tratamento antimicrobiano apresentou, numericamente, os melhores valores para digestibilidade de todos os nutrientes e também para a energia bruta da dieta. Esses resultados comprovam o efeito dos antimicrobianos em promover maior digestibilidade dos nutrientes da dieta (OETTING et al., 2006).

Os menores coeficientes de digestibilidade aparente dos nutrientes e energia bruta da dieta podem estar relacionados à inclusão da própolis ser feita na sua forma bruta, a presença de cera, pólen e outras substâncias orgânicas podem ter complexado os nutrientes e diminuído seu aproveitamento pelo animal. 







\subsection{Frequência de diarreia}

Os resultados para a frequência de diarreia nos leitões durante o período de 35 dias de experimentação são apresentados na Tabela 4. Não foi observada diferença significativa $(\mathrm{p}>0,05)$ para os tratamentos sem e/ou com inclusão de própolis e probiótico em comparação ao tratamento antimicrobiano para a frequência de diarreia. $\mathrm{O}$ tratamento $\mathrm{P}+\mathrm{PRO}$ apresentou resultado numericamente inferior para a frequência de diarreia na primeira semana de experimentação. Por outro lado, o tratamento antimicrobiano apresentou valores numericamente inferiores para a frequência de diarreia para os períodos de 7 a 21 dias e 21 a 35 dias. Os resultados obtidos no tratamento com inclusão do antimicrobiano comprovam a capacidade dos antimicrobianos em controlar a ocorrência de diarreia em leitões em fase de creche (OETTING et al., 2006).

Dierckx e Funari (1999) não observaram diferença entre os tratamentos controle e com níveis crescentes de própolis sobre a incidência de diarreia. Entretanto, a inclusão de probióticos à base de Bacillus cereus e de Enterococcus faecium em dietas para leitões recémdesmamados foi capaz de minimizar significativamente a incidência da diarreia pós-desmame, quando comparados ao tratamento controle (MACHA et al., 2004; TARAS et al., 2005, 2006). Huang et al. (2004) constataram que a adição de um complexo probiótico à base de Lactobacillus spp. em dietas para leitões desafiados com Escherichia coli preveniu a incidência de diarreia. 







\subsection{Morfometria e peso de órgãos}

Os resultados para peso de abate, peso absoluto e peso relativo de órgãos, comprimento e densidade do intestino delgado de leitões aos 35 dias de experimentação são apresentados na Tabela 5.

Não foram constatadas diferenças significativas para as variáveis de peso de abate, comprimento e densidade do intestino delgado $(\mathrm{p}>0,05)$. Entretanto, o peso absoluto e relativo do intestino no tratamento $\mathrm{P}+\mathrm{PRO}$ diferiu significativamente do tratamento antimicrobiano $(\mathrm{p}<0,05)$. A combinação entre própolis e probiótico aumentou o peso absoluto e relativo do intestino $(p<0,05)$, mas não alterou significativamente seu comprimento $(p>0,05)$, sendo possível apenas observar uma diferença numérica. O maior peso do intestino pode estar relacionado a um maior diâmetro ou espessura do tubo intestinal.

Aumento da espessura da mucosa do íleo de leitões foi observada por Bontempo et al. (2006) e Di Giancamillo et al. (2008) ao incluírem probióticos à base de Saccharomyces cerevisiae ssp. e de Pediococcus acidilactici em dietas de leitões desmamados. Entretanto, a utilização de probiótico isolado não promoveu o mesmo resultado neste experimento.

Eyng et al. (2014) constataram que a inclusão de própolis em dietas para frangos de corte alterou o peso do proventrículo e apresentou variação de peso com a inclusão de níveis crescentes de extrato de própolis. 







\subsection{Histologia do epitélio intestinal}

Os resultados para altura de vilosidade, profundidade de cripta e relação altura da vilosidade e profundidade de cripta do duodeno de leitões aos 35 dias de experimentação são apresentados na Tabela 6. Não foi observada diferença significativa $(p>0,05)$ para os tratamentos sem e/ou com inclusão de própolis e probiótico em comparação ao tratamento antimicrobiano para as referidas variáveis histológicas do duodeno.

A suplementação de probiótico, contendo Enterococcus faecium, Lactobacillus salivarius, Lactobacillus reuteri e Bifidobacterium thermophilum, alterou significativamente a altura de vilosidade no duodeno de leitões (MAIR et al., 2010). Alterações na altura de vilosidade e profundidade de cripta também foram observadas com a inclusão de probióticos à base de Saccharomyces cerevisiae ssp. e de Pediococcus acidilactici, associadas com diminuição da relação vilosidade:cripta e aumento da espessura da mucosa do íleo de leitões (BONTEMPO et al., 2006; DI GIANCAMILLO et al., 2008). Contudo, Le Bon et al. (2010) encontraram que a adição de probióticos à base de Saccharomyces cerevisiae ssp. e de Pediococcus acidilactici em dietas para leitões, não afeta a profundidade de cripta e espessura da mucosa.

A própolis bruta adicionada em níveis crescentes em dietas para frangos de corte, não influenciou a altura de vilosidade, profundidade de cripta e relação altura de vilosidade e profundidade de cripta do duodeno e jejuno de frangos de corte com 7 e 21 dias, porém foi constatada variação na profundidade de cripta no íleo aos 21 dias de experimentação (DUARTE et al., 2014). A utilização de extrato de própolis em níveis crescentes alterou a altura de vilosidade, profundidade de cripta e relação altura de vilosidade e profundidade de cripta no duodeno de frangos de corte com 21, mas não foram observadas alterações no jejuno e íleo (EYNG et al., 2014). 







\subsection{Microbiologia do conteúdo intestinal}

Os resultados para a contagem bacteriana do conteúdo intestinal dos segmentos referentes ao jejuno e ceco de leitões aos 35 dias de experimentação são apresentados na Tabela 7.

A análise microbiológica do conteúdo do jejuno de leitões revelou que a inclusão do probiótico, aumentou a contagem de bactérias do gênero Enterococcus $(\mathrm{p}<0,05)$, sendo a contagem dessas bactérias, nos tratamentos PRO e P+PRO, superior em comparação ao tratamento antimicrobiano. A inclusão de probiótico à base de Enterococcus faecium em dietas para leitões recém-desmamados influencia na microbiota do conteúdo intestinal do jejuno em relação ao gênero Enterococcus, representando efetividade da colonização das bactérias desse gênero provenientes do probiótico. Observou-se também que a própolis bruta diminuiu a contagem de bactérias do gênero Lactobacillus, evidenciando que a inclusão da própolis, isolada ou em combinação com o probiótico, inviabiliza as bactérias do gênero Lactobacillus $(\mathrm{p}<0,05)$.

No conteúdo do ceco, a contagem de bactérias do gênero Enterococcus no tratamento $\mathrm{P}$ foi superior em relação ao tratamento antimicrobiano $(p<0,05)$. O tratamento com inclusão do antimicrobiano apresentou a menor contagem de bactérias para esse gênero de bactérias, o que pode remeter a ação do antimicrobiano como modificador da microbiota intestinal. $\mathrm{O}$ tratamento antimicrobiano apresentou diminuição da contagem de bactérias do gênero Lactobacillus em comparação ao outros tratamentos ( $<<0,05)$, evidenciando mais uma vez a capacidade dos antimicrobianos em modificar a microbiota intestinal.

Oetting et al. (2006) e Pedroso et al. (2005) ressaltam a capacidade dos antimicrobianos em modificar a microbiota intestinal e não atuar na redução de microrganismos.

Franklin et al. (2002) observaram uma tendência da população de Lactobacillus em leitões desmamados ser maior no ceco $\left(9,75 \log _{10} \mathrm{UFC} / \mathrm{g}\right)$ comparativamente com o íleo $(9,08$ $\log _{10} \mathrm{UFC} / \mathrm{g}$ ) e ocorrência de população intermediária no jejuno.

Huang et al. (2004) constataram que a inclusão de um complexo probiótico à base de Lactobacillus spp. diminuiu a contagem de Escherichia coli nas seções do trato gastrintestinal de leitões recém-desmamados. A maior presença de espécies do gênero Lactobacillus é sugestiva de que ao apresentar a capacidade de ligar-se à superfície do epitélio intestinal, desenvolveram o efeito da exclusão competitiva (SILVA et al., 2007; TANNOCK, 1997).

Le Bon et al. (2010) também observaram redução na contagem de Escherichia coli em leitões que receberam probióticos à base de Saccharomyces cerevisiae ssp. e Pediococcus 
acidilactici, entretanto não foi observada diferença na contagem de Lactobacillus, mas em função da diminuição da contagem de coliformes, ocorreu melhora na relação lactobacilos/coliformes, que representa um indicador de saúde intestinal. 
in






\section{CONCLUSÃO}

A combinação de própolis bruta e probiótico em dietas para leitões recém-desmamados não apresenta a capacidade de eliminar microrganismos indesejáveis e, consequentemente, possibilitar a colonização do trato gastrointestinal por bactérias do gênero Lactobacillus, conferindo melhor desempenho animal. 


\section{REFERÊNCIAS}

AFIP. ARMED FORCES INSTITUTE OF PATHOLOGY. Laboratory Methods in Histotechnology, Washington: AFIP, 1994. 274p.

ALENCAR, S.M.; OLDONI, T.L.C.; CASTRO, M.L.; CABRAL, I.S.R.; COSTA-NETO, C.M.; CURY, J.A.; ROSALEN, P.L.; IKEGAKI, M. Chemical compositions and biological activity of a new type of Brazilian propolis: Red propolis. Journal of Ethnopharmacology, Lausanne, v. 113, n. 2, p. 278-283, 2007.

ALLAN, P.; BILKEI, G. Oregano improves reproductive performance of sows. Theriogenology, Los Altos, v. 63, n. 3, p. 716-721, 2005.

AL-WAILI, N.; AL-GHAMDI, A.; ANSARI, M. J.; AL-ATTAL, Y.; SALOM, K. Synergistic effects of honey and propolis toward drug multi-resistant Staphylococcus aureus, Escherichia coli and Candida albicans isolates in single and polymicrobial cultures.

International Journal of Medical Sciences, Australia, v. 9, n. 9, p. 793-800, 2012.

BANKOVA, V. Chemical diversity of propolis makes it a valuable source of new biologically active compounds. Journal of ApiProduct and ApiMedical Science,Cidade, [s.1.], v. 1, n. 2, p. 23-28, 2009.

BEDFORD, M. Removal of antibiotic growth promoters from poultry diets: implications and strategies to minimize subsequent problems. World's Poultry Science Journal, Cambridge, v. 56, p. 348-365, 2000.

BERNARDEAU, M.; VERNOUX, J.P. Overview of differences between microbial feed additives and probiotics for food regarding regulation, growth promotion effects and health properties and consequences for extrapolation of farm animal results to humans. Clinical microbiology and infection: the official publication of the European Society of Clinical Microbiology and Infectious Diseases, Paris, v. 19, n. 4, p. 321-330, Abr. 2013.

BERNARDEAU, M.; VERNOUX, J.P.; HENRI-DUBERNET, S.; GUEGUEN, M. Safety assessment of dairy microorganisms: the Lactobacillus genus. International Journal of Food Microbiology, Amsterdam, v. 126, n. 3, p. 278-285, 2008.

BEYRAGHDAR KASHKOOLI, O.; EBRAHIMI DORCHEH, E.; MAHBOOBI-SOOFIANI, N.; SAMIE, A. Long-term effects of propolis on serum biochemical parameters of rainbow trout (Oncorhynchus mykiss). Ecotoxicology and Environmental Safety, New York, v. 74, n. 3, p. 315-318, 2011.

BHANDARI, S.K; OPAPEJU, F.O.; KRAUSE, D.O; NYACHOTI, C.M. Dietary protein level and probiotic supplementation effects on piglet response to Escherichia coli K88 challenge: Performance and gut microbial population. Livestock Science, Amsterdam, v. 133, n. 1-3, p. 185-188, 2010.

BIANCHINI, L.; BEDENDO, I.P. Efeito antibiótico da própolis sobre bactérias fitopatogênicas. Scientia Agricola, Piracicaba, v. 55, n. 1, p. 149-152, 1998. 
BIAVATTI, M.W.; BELLAVER, M.H.; VOLPATO, L.; COSTA, C.; BELLAVER, C. Preliminary studies of alternative feed additives for broilers: Alternanthera brasiliana extract, propolis extract and linseed oil. Revista Brasileira de Ciência Avícola, Campinas, v. 5, n. 2, p. 147-151, 2003.

BONTEMPO, V.; DI GIANCAMILLO, A.; SAVOINI, G.; DELL'ORTO, V.; DOMENEGHINI, C. Live yeast dietary supplementation acts upon intestinal morphofunctional aspects and growth in weanling piglets. Animal Feed Science and Technology, Amsterdam, v. 129, n. 3/4, p. 224-236, 2006.

BORCHERS, A.T.; SELMI, C.; MEYERS, F.J.; KEEN, C.L.; GERSHWIN, M.E. Probiotics and immunity. Journal of Gastroenterology, Tokyo, v. 44, p. 26-46, 2009.

BOSI, P.; MERIALDI, G.; SCANDURRA, S.; MESSORI, S.; BARDASI, L.; NISI, I.; RUSSO, D.; CASINI, L.; TREVISI, P. Feed supplemented with 3 different antibiotics improved food intake and decreased the activation of the humoral immune response in healthy weaned pigs but had differing effects on intestinal microbiota. Journal of Animal Science, Champaign, v. 89, p. 4043-4053, 2011.

BOUDRY, G.; PERON, V.; LE HUEROU-LURON, I.; LALLÈS, J. P.; SEVE, B. Weaning induces both transient and long-lasting modifications of absorptive, secretory, and barrier properties of piglet intestine. Journal of Nutrition, Philadelphia, v. 134, n. 9, p. 2256-2262, 2004.

BÚFALO, M.C.; CANDEIAS, J.M.G.; SFORCIN, J.M.; In vitro cytotoxic effect of Brazilian green propolis on human laryngeal epidermóide carcinoma (HEp-2) cells. Evidence-based Complementary and Alternative Medicine, Oxford, v. 6, n.4, p. 483-487, 2009a.

BÚFALO, M.C.; FIGUEIREDO, A.S.; SOUSA, J.P.B.; CANDEIAS, J.M.G.; BASTOS, J.K.; SFORCIN, J.M. Anti-poliovirus activity of Baccharis dracunculifolia and propolis by cell viability determination and real-time PCR. Journal of Applied Microbiology, Oxford, v. 107, n. 5, p. 1669-1680, 2009 b.

BURDOCK, G.A. Review of the biological properties antitoxicity of bee propolis. Food and Chemical Toxicology, Oxford, v. 36, n. 4, p. 347-363, 1998.

CAMPOS, J. F.; DOS SANTOS, U.P.; MACORINI, L.F.B.; DE MELO, A.M.M.F.; BALESTIERI, J.B.P.; PAREDES-GAMERO, E.J.; CARDOSO, C.A.L.; DE PICOLI SOUZA, K.; DOS SANTOS, E.L. Antimicrobial, antioxidant and cytotoxic activities of propolis from Melipona orbignyi (Hymenoptera, Apidae). Food and Chemical Toxicology, Oxford, v. 65, p. 374-380, 2014.

CASTRO, M.L.; CURY, J.A; ROSALEN, P.L. Própolis do sudeste e nordeste do Brasil: influência da sazonalidade na atividade antibacteriana e composição fenólica. Química Nova, São Paulo, v. 30, n. 7, p. 1512-1516, 2007.

ÇETIN, E.; SILICI, S.; ÇETIN, N.; GÜÇLÜ, B.K. Effects of diets containing different concentrations of propolis on hematological and immunological variables in laying hens. Poultry Science, Savoy, v. 89, n. 8, p. 1703-1708, 2010. 
CHANG, Y.H.; KIM, J.K.; KIM, H.J.; KIM, W.Y.; KIM, Y.B.; PARK, Y.H. Selection of a potential probiotic Lactobacillus strain and subsequent in vivo studies. Antonie Van

Leeuwenhoek, Wageningen, v. 80, n. 2, p. 193-199, 2001.

COELHO, M.S.; SILVA, J.H.V.; OLIVEIRA, E.R.A.; AMÂNCIO, A.L.L.; SILVA, N. V.; LIMA, R.M.B. A própolis e sua utilização em animais de produção. Archivos de Zootecnia, Córdoba, v. 59, p. 95-112, 2010.

COLLADO, M.C.; ISOLAURI, E.; SALMINEN, S.; SANZ, Y. The impact of probiotic on gut health. Current Drug Metabolism, Hilversum, v. 10, n. 1, p. 68-78, 2009.

COLLINGTON, G.K.; PARKER, D.S.; ARMSTRONG, D.G. The influence of inclusion of either an antibiotic or a probiotic in the diet on the development of digestive enzyme activity in the pig. The British Journal of Nutrition, Cambridge, v. 64, n. 1, p. 59-70, 1990.

COLONI, R.D.; LUI, J.F.; DOS SANTOS, E.; CAVALCANTE NETO, A.; ZANATO, J.A. F.; SILVA, L.P.G.; MALHEIROS, E.B. Extrato etanólico de própolis sobre o ganho de peso, parâmetros de carcaça e pH cecal de coelhos em crescimento. Biotemas, Florianópolis, v. 20, n. 2, p. 59-64, 2007.

CROMWELL, G.L. Why and how antibiotics are used in swine production. Animal Biotechnology, New York, v. 13, p. 7-27, 2002.

DANESHMAND, A.; SADEGHI, G.; KARIMI, A.; VAZIRY, A.; IBRAHIM, S.A. Evaluating complementary effects of ethanol extract of propolis with the probiotic on growth performance, immune response and serum metabolites in male broiler chickens. Livestock Science, Amsterdam, v. 178, p. 195-201, 2015.

DE ANGELIS, M.; SIRAGUSA, S.; BERLOCO, M.; CAPUTO, L.; SETTANNI, L.; ALFONSI, G.; AMERIO, M.; GRANDI, A.; RAGNI, A.; GOBBETTI, M. Selection of potential probiotic lactobacilli from pig feces to be used as additives in pelleted feeding. Research in microbiology, Amsterdam, v. 157, n. 8, p. 792-801, 2006.

DE VRESE, M.; STEGELMANN, A.; RICHTER, B.; FENSELAU, S.; LAUE, C.; SCHREZENMEIR, J. Probiotics-compensation for lactase insufficiency. The American Journal of Clinical Nutrition, Bethesda, v. 73, suppl. 2, p. 421-429, 2001.

DENLI, M.; CANKAYA, S.; SILICI, S.; OKAN, F.; ULUOCAK, A.N. Effect of dietary addition of Turkish propolis on the growth performance, carcass characteristics and serum variables of quail (Coturnix coturnix japonica). Asian-Australasian Journal of Animal Sciences, Seoul, v. 18, n. 6, p. 848-854, 2005.

DI GIANCAMILLO, A.; VITARI, F.; SAVOINI, G.; BONTEMPO, V.; BERSANI, C.; DELL'ORTO, V.; DOMENEGHINI, C. Effects of orally administered probiotic Pediococcus acidilactici on the small and large intestine of weaning piglets. A qualitative and quantitative microanatomical study. Histology and Histopathology, Murcia, v. 23, n. 6, p. 651-664, 2008.

DIBNER, J.J.; RICHARDS, J.D. Antibiotic growth promoters in agriculture: history and mode of action. Poultry Science, Oxford, v. 84, n. 4, p. 634-643, 2005. 
DIERCKX, S.M.A.G.; FUNARI, S.R.C. Uso da própolis na alimentação de leitões desmamados como aditivo e na prevenção à diarréia. Archivos Latinoamericanos de Produccion Animal, Mayagüez, v. 7, n. 2, p. 109-116, 1999.

DOMENEGHINI, C.; DI GIANCAMILLO, A.; ARRIGHI, S.; BOSI, G. Gut-trophic feed additives and their effects upon the gut structure and intestinal metabolism. State of the art in the pig, and perspectives towards humans. Histology and Histopathology, Murcia, v. 21, n. 3, p. 273-283, 2006.

DUARTE, C.R.A.; EYNG, C.; MURAKAMI, A.E.; SANTOS, T.C. Intestinal morphology and activity of digestive enzymes in broilers fed crude propolis. Canadian Journal of Animal Science, Ottawa, v. 94, n. 1, p. 105-114, 2014.

EYNG, C.; MURAKAMI, A.E.; DUARTE, C.R.A.; SANTOS, T.C. Effect of dietary supplementation with an ethanolic extract of propolis on broiler intestinal morphology and digestive enzyme activity. Journal of Animal Physiology and Animal Nutrition, Berlin, v. 98, n. 2, p. 393-401, 2014.

EYNG, C.; MURAKAMI, A.E.; PEDROSO, R.B.; SILVEIRA, T.G.V.; LOURENÇO, D. A.L.; GARCIA, A.F.Q.M. Crude propolis as an immunostimulating agent in broiler feed during the starter phase. Semina: Ciências Agrárias, Londrina, v. 34, n. 5, p. 2511-2522, 2013.

FEDALTO, L.M.; TKACZ, M.; ADER, L.P. Probióticos na alimentação de leitões do desmame aos 63 dias de idade. Archives of Veterinary Science, Curitiba, v. 7, n. 1, p. 83-88, 2002.

FRANCO, S.D.S.; ROSA, A.P.; LENGLER, S.; UTTPATEL, R.; ZANELLA, I.; GRESSLER, C.; SOUZA, H.M. Índices produtivos e rendimento de carcaça de frangos de corte alimentados com dietas contendo níveis de extrato etanólico de própolis ou promotores de crescimento convencionais. Ciência Rural, Santa Maria, v. 37, n. 6, p. 1765-1771, 2007.

FRANKLIN, M.A.; MATHEW, A.G.; VICKERS, J.R.; CLIFT, R.A. Characterization of microbial populations and volatile fatty acid concentrations in the jejunum, ileum, and cecum of pigs weaned at 17 vs 24 days of age. Journal of Animal Science, Champaign, v. 80, n. 11, p. 2904-2910, 2002.

FREITAS, J.A.; VANAT, N.; PINHEIRO, J.W.; BALARIN, M.R.; SFORCIN, J.M.; VENANCIO, E.J. The effects of propolis on antibody production by laying hens. Poultry Science, Oxford, v. 90, n. 6, p. 1227-1233, 2011.

FREITAS, S.F.; SHINOHARA, L.; SFORCIN, J.M.; GUIMARÃES, S. In vitro effects of propolis on Giardia duodenalis trophozoites. Phytomedicine, Stuttgart, v. 13, n. 3, p. 170$175,2006$.

FULLER, R. Probiotics in man and animals, Journal of Applied Bacteriology, Oxford, v. 66, n. 5 , p. $365-378,1989$.

FUNARI, C.S.; FERRO, V. O. Análise de própolis. Ciência e Tecnologia de Alimentos, Campinas, v. 26, n. 1, p. 171-178, 2006. 
GARCIA, R.C.; DE SÁ, M.E.P.; LANGONI, H.; FUNARI, S.R.C. Efeito do extrato alcoólico de própolis sobre o perfil bioquímico e o desempenho de coelhos jovens. Acta Scientiarum. Animal Sciences, Maringá, v. 26, n. 1, p. 57-67, 2004.

GASKINS, H.R.C.; COLLIER, T.; ANDERSON, D.B. Antibiotics as growth promotants: Mode of action. Animal Biotechnology, New York, v. 13, n. 1, p. 29-42, 2002.

GEKKER, G.; HU, S.; SPIVAK, M.; LOKENSGARD, J.R.; PETERSON, P K. Anti-HIV-1 activity of propolis in CD4(+) lymphocyte and microglial cell cultures. Journal of Ethnopharmacology, Lausanne, v. 102, n. 2, p. 158-163, 2005.

GHISALBERTI, E.L. Propolis: a review. Bee World, [s.1], v. 60, n. 2, p. 59-84, 1979.

GIANG, H.H.; VIET, T. Q.; OGLE, B.; LINDBERG, J.E. Effects of different probiotic complexes of lactic acid bacteria on growth performance and gut environment of weaned piglets. Livestock Science, Amsterdam, v. 133, n. 1/3, p. 182-184, 2010.

GIROUX, S.; GUY-PIERRE, M.; ROBERT, S. Relationships between individual behavioural traits and post-weaning growth in segregated early-weaned piglets. Applied Animal

Behavior Science, Amsterdam, v. 70, n. 1, p. 41-48, 2000.

HUANG, C.; QIAO, S.; LI, D.; PIAO, X.; REN, J. Effects of lactobacilli on the performance, diarrhea incidence, VFA concentration and gastrointestinal microbial flora of weaning pigs.

Asian-Australasian Journal of Animal Sciences, Seoul, v. 17, n. 3, p. 401-409, 2004.

HUGUET, A.; SÈVE, B.; LE DIVIDICH, J.; LE HUËROU-LURON, I. Effects of a bovine colostrum-supplemented diet on some gut parameters in weaned piglets. Reproduction Nutrition Development, Paris, v. 46, n. 2, p. 167-178, 2006.

INOUE, T.H.; SOUSA, E.A.; ORSI, R.O.; FUNARI, S.R.C.; BARRETO, L.M.R.C.; SILVA, A.P. Produção de própolis por diferentes métodos de coleta. Archivos Latinoamericanos de Producción Animal, Mayaguez, v. 15, n. 2, p. 65-69, 2007.

ISOLAURI, E.; SALMINEN, S.; OUWEHAND, A.C. Microbial-gut interactions in health and disease. Probiotics. Best Practice \& Research. Clinical Gastroenterology, London, v. 18, n. 2, p. 299-313, 2004.

ITO, E.H.; SILVA, N.V.P.; ORSI, R.O.; BERTO, D.A.; GOMES, S.M.A. Uso da própolis em ração de leitões desmamados. PUBVET, Londrina, v. 3, n. 4, 10p.2009.

JAHANBAKHSH, S.; KABORE, K.P.; FRAVALO, P.; LETELLIER, A.; FAIRBROTHER, J.M. Impact of medicated feed along with clay mineral supplementation on Escherichia coli resistance to antimicrobial agents in pigs after weaning in field conditions. Research in Veterinary Science, Oxford, v. 102, p. 72-79, 2015.

JAMROZ, D.; WERTELEKI, T.; HOUSZKA, M.; KAMEL, C. Influence of diet type on the inclusion of plant origin active substances on morphological and histochemical characteristics of the stomach and jejunum walls in chicken. Journal of Animal Physiology and Animal Nutrition, Berlin, v. 90, n. 5/6, p. 255-268, 2006.

JIN, L. Z.; HO, T. W.; ABDULLAH, N.; JALALUDIN, S. Probiotics in poultry: modes of action. World's Poultry Science Journal, Columbus, v. 53, n. 4, p. 351-368, 1997. 
JIN, L.Z.; MARQUARDT, R.R.; BAIDOO, S.K. Inhibition of enterotoxigenic Escherichia coli K88, K99 and 987P by the Lactobacillus isolates from porcine intestine. Journal of the Science of Food and Agriculture, London, v. 80, n. 5, p. 619-624, 2000.

JOHNSTON, A.M. Animals and antibiotics. International Journal of Antimicrobial Agents, Amsterdam, v. 18, n. 3, p. 291-294, 2001.

JUKNA, C.; JUKNA, V.; ŠIMKUS, A. The effect of probiotics and phytobiotics on meat properties and quality in pigs. Veterinarija ir Zootechnika, Kaunas, v.51, p. 80-84, 2005.

JURD, L.; GEISSMAN, T.A. Absorption spectra of metal complexes of flavonoid compounds. Journal of Organic Chemistry, Easton, v. 21, n. 12, p.1395-1401, 1956.

KAČÁNIOVÁ, M.; ROVNÁ, K.; ARPÁŠOVÁ, H.; CUBOŇ, J.; HLEBA, L.; POCHOP, J.; KUNOVÁ, S.; HAŠČÍK, P. In vitro and in vivo antimicrobial activity of propolis on the microbiota from gastrointestinal tract of chicken. Journal of Environmental Science and Health. Part A, Toxic/Hazardous Substances \& Environmental Engineering, New York, v. 47, n. 11, p. 1665-1671, 2012.

KELLEY, T.R.; PANCORBO, O.C.; MERKA, W.C.; BARNHARTS, H.M. Antibiotic resistance of bacterial litter isolates. Poultry Science, Oxford, v. 77, n. 2, p. 243-247, 1998.

KONSTANTINOV, S.R.; AWATI, A.; SMIDT, H.; WILLIAMS, B.A.; AKKER- MANS, A.D.L.; DEVOS, W.M. Specific response of a novel and abundant Lactobacillus amylovoruslike phylotype to dietary prebiotics in the guts of weaning piglets. Applied and

Environmental Microbiology, Washington, v. 70, n. 7, p. 3821-3830, 2004.

KORU, O.; TOKSOY, F.; ACIKEL, C.H; TUNCA, Y.M.; BAYSALLAR, M.; USKUDAR GUCLU, A.; AKCA, E.; OZKOK TUYLU, A.; SORKUN, K.; TANYUKSEL, M.; SALIH, B. In vitro antimicrobial activity of propolis samples from different geographical origins against certain oral pathogens. Anaerobe, London, v. 13, n. 3/4, p. 140-145, 2007.

KOZASA, M. Toyocerin (Bacillus toyoi) as growth promotor for animal feeding. Microbiology Aliments Nutrition, Chatenay-Malabrys, n. 4, p. 121-135, 1986.

KUJUMGIEV, A.; TSVETKOVA, I.; SEKLEDJIEVA, Y.; BANKOVA, V.; CHRISTOV, R.; POPOV, S. Antibacterial, antifungal and antiviral activity of propolis of different geographic origin. Journal of Ethnopharmacology, Lausanne, v. 64, n. 3, p. 235-240, 1999.

KYRIAKIS, S.C.; TSILOYIANNIS, V.K.; VLEMMAS, J.; SARRIS, K.; TSINAS, A.C.; ALEXOPOULOS, C.; JANSEGERS, L. The effect of probiotic LSP 122 on the control of post-weaning diarrhea syndrome of piglets. Research in Veterinary Science, Oxford, v. 67, n. 3, p. 223-228, 1999.

LALLÈS, J.P.; BOSI, P.; SMIDT, H.; STOKES, CR. Weaning - a challenge to gut physiologists. Livestock Science, Amsterdam, v. 108, n. 1/3, p. 82-93, 2007.

LANA, R.P.; CAMARDELLI, M.M.L.; QUEIROZ, A.C.; RODRIGUES, M.T.; EIFERT, E.C.; MIRANDA, E.N.; ALMEIDA, I.C.C. Óleo de soja e própolis na alimentação de cabras leiteiras. Brasileira de Zootecnia, Viçosa, v. 34, n. 2, p. 650-658, 2005. 
LE BON, M.; DAVIES, H.E.; GLYNN, C.; THOMPSON, C.; MADDEN, M.; WISEMAN, J.; DODD, C.E.R.; HURDIDGE, L.; PAYNE, G.; LE TREUT, Y.; CRAIGON, J.;

TÖTEMEYER, S.; MELLITS, K.H. Influence of probiotics on gut health in the weaned pig. Livestock Science, Amsterdam, v. 133, n. 1/3, p. 179-181, 2010.

LIMA, A.C.F.; JÚNIOR, J.M.P.; MACARI, M.; MALHEIROS, E.B. Efeito do uso de probiótico sobre o desempenho e atividade de enzimas digestivas de frangos de corte. Revista Brasileira de Zootecnia, Viçosa, v. 32, n. 1, p. 200-2007, 2003.

LODDI, M.M.; GONZALES, E.; TAKITA, T.S.; MENDES, A.A.; ROÇA, R.O. Uso de probiótico e antibiótico sobre o desempenho, o rendimento e a qualidade de carcaça de frangos de corte. Revista Brasileira de Zootecnia, Viçosa, v. 29, n. 4, p. 1124-1131, 2000.

LUSTOSA, S.R.; GALINDO, A.B.; NUNES, L.C.C.; RANDAU, K.P.; ROLIM NETO, P. J. Propolis: updates on chemistry and pharmacology. Brazilian Journal of Pharmacognosy, João Pessoa, v. 18, n. 3, p. 447-454, 2008.

MACHA, M.; TARAS, D.; VAHJEN, W.; ARINI, A.; SIMON, O. Specific enumeration of the probiotic strain Enterococcus faecium NCIMB 10415 in the intestinal tract and in faeces of piglets and sows. Archives of Animal Nutrition, Abingdon, v. 58, n. 6, p. 443-452, 2004.

MADEC, F.; JOSSE, J.; CHANTAL, A. Evaluation d'une methode multifactorielle dans L'analyse des troubles digestifs du sevrage. Journees de la Recherche Porcine en France, Paris, v. 14, p. 379-386, 1982.

MAIR, C.; PLITZNER, C.; PFAFFL, M.W.; SCHEDLE, K.; MEYER, H.H.; WINDISCH, W. Inulin and probiotics in newly weaned piglets: effects on intestinal morphology, mRNA expression levels of inflammatory marker genes and haematology. Archives of Animal Nutrition, Abingdon, v. 64, n. 4, p. 304-321, 2010.

MARCUCCI, M.C. Propriedades biológicas e terapêuticas dos constituintes químicos da própolis. Química Nova, São Paulo, v. 19, n. 5, p. 529-536, 1996.

MARCUCCI, M.C.; FERRERES, F.; GARCÍA-VIGUERA, C.; BANKOVA, V.S.; DE CASTRO, S.L.; DANTAS, A.P.; VALENTE, P.H.M.; PAULINO, N. Phenolic compounds from brazilian propolis with pharmacological activities. Journal of Ethnopharmacology, Lausanne, v. 74, n. 2, p. 105-112, 2001.

MATTERSON, L.D.; POTTER, L.M.; STUTZ, M.W.; SINGSEN, E.P. The metabolizable energy of feed ingredients for chickens. Storrs: University of Connecticut, 1965. 11p.

MELLOR, S. Alternatives to antibiotic. Pig Progress, Doetinchem, v. 16, p. 18-21, 2000.

MENEZES, H. Própolis: uma revisão dos recentes estudos de suas propriedades farmacológicas. Arquivos do Instituto Biológico, São Paulo, v. 72, n.3, p. 405-411, 2005.

MENTEN, J.F.M. Probióticos, prebióticos e aditivos fitogênicos na nutrição de aves. In: SIMPÓSIO SOBRE INGREDIENTES NA ALIMENTAÇÃO ANIMAL, 2., 2002, Uberlândia. Anais... Campinas: Colégio Brasileiro de Nutrição Animal, 2002. p. 251-276. 
MERESTA, L.; MERESTA, T.; BURDZINSKI, J.; CHMURZYNSKI, P. Treatment of mastitis in cows using an extract of propolis. Medycyna Weterinaryjna, Wrocław, v. 45, n. 7, p. 392-395, 1989.

METZLER, B.; BAUER, E.; MONSENTH, R. Microflora management in the gastrointestinal of piglets. Asian-Australasian Journal of Animal Sciences, Seoul, v.18, n. 9, p.1353-1362, 2005.

MOT, D.; TÎRZIU, E.; NICHITA, I. Study of bactericidal properties of propolis. Scientific Papers: Animal Science and Biotechnologies, Timisoara, v. 47, n. 1, p. 256-259, 2014.

MUHL, A.; LIEBERT, F. Growth and parameters of microflora in intestinal and faecal samples of piglets due to application of a phytogenic feed additive. Journal of Animal Physiology and Animal Nutrition, Berlin, v. 91, n. 9-10, p. 411-418, 2007.

NABUURS, M.J.A; HOOGENDOORN, A.; VAN DER MOLEN, E.J.; VAN OSTA, A.L. M. Villus height and crypt depth in weaned and unweaned pigs, reared under various circumstances in the Netherlands. Research in Veterinary Science, Oxford, v. 55, n. 1, p.7884, 1993.

NAIDU, A.S.; BIDLACK, W.R.; CLEMENS, R.A. Probiotic spectra of lactic acid bacteria (LAB). Critical Reviews in Food Science and Nutrition, Boca Raton, v. 38, n. 1, p. 13-126, 1999.

NAKAMURA, R.; NAKAMURA, R.; WATANABE, K.; OKA, K.; OHTA, S.; MISHIMA, S.; TESHIMA, R. Effects of propolis from different areas on mast cell degranulation and identification of the effective components in propolis. International Immunopharmacology, Amsterdam, v. 10, n. 9, p. 1107-1112, 2010.

NEDJI, N.; LOUCIF-AYAD, W. Antimicrobial activity of Algerian propolis in foodborne pathogens and its quantitative chemical composition. Asian Pacific Journal of Tropical Disease, Haikou, v. 4, n. 6, p. 433-437, 2014.

NG, S.C.; HART, A.L.; KAMM, M.A.; STAGG, A.J.; KNIGHT, S.C. Mechanisms of action of probiotics: recent advances. Inflammatory Bowel Diseases, New York, v. 15, n. 2, p. 300 $310,2009$.

NIEWOLD, T.A. Intestinal genomics for evaluation of alternatives for AGP, current situation and perspectives. In: BARUG, D.; JONG, J.; KIES, A.K.; VERSTEGEN, M. (Ed.).

Antimicrobial Growth Promoters: Where Do We Go from Here? Wageningen:

Wageningen Academic Publishers, 2006. p. 361-368.

NIEWOLD, T.A. The nonantibiotic anti-inflammatory effect of antimicrobial growth promoters, the real mode of action? A hypothesis. Poultry Science, Oxford, v. 86, n. 4, p. 605-609, 2007.

NRC. NATIONAL RESEARCH COUNCIL. Nutrient Requirements of Swine. 11.ed. Washington: National Academy Press, 2012. 400p. 
OETTING, L.L.; UTIYAMA, C.E.; GIANI, P.A.; RUIZ, U.S.; MIYADA, V.S. Efeitos de antimicrobianos e extratos vegetais sobre a microbiota intestinal e a frequência de diarreia em leitões recém-desmamados. Revista Brasileira de Zootecnia, Viçosa, v. 35, n. 5, p. 2013 2017, 2006.

OGAWA, M.; SHIMIZU, K.; NOMOTO, K.; TANAKA, R.; HAMABATA, T.; YAMASAKI, S.; TAKEDA, T.; TAKEDA, Y. Inhibition of in vitro growth of Shiga toxinproducing Escherichia coli O157:H7 by probiotic Lactobacillus strains due to production of lactic acid. International Journal of Food Microbiology, Amsterdam, v. 68, n. 1/2, p. 135 $140,2001$.

OLDONI, T.L. C. Isolamento e identificação de compostos com atividade antioxidante de uma nova variedade de própolis brasileira produzida por abelhas da espécie Apis mellifera. 2007. 104p. Dissertação (Mestrado em Ciência e Tecnologia de Alimentos) Escola Superior de Agricultura "Luiz de Queiroz", Universidade de São Paulo, Piracicaba, 2007.

OLIVEIRA, K.A.M.; OLIVEIRA, G.V.; BATALINA, C.; ROSALEM, J.A.; RIBEIRO, L. S. Atividade antimicrobiana e quantificação de flavonoides e fenóis totais em diferentes extratos de própolis. Semina: Ciências Biológicas e da Saúde, Londrina, v. 33, n. 2, p. 211-222, 2012.

ORSI, R.O.; FUNARI, S.R.C.; SOARES, A.M.V.C.; CALVI, S.A.; OLIVEIRA, S.L.; SFORCIN, J.M.; BANKOVA, V. Immunomodulatory action of propolis on macrophage activation. Journal of Venomous Animals and Toxins, Botucatu, v. 6, n.2, p. 205-219, 2000 .

ORSI, R. O.; SFORCIN, J.M.; FUNARI, S.R.C.; BANKOVA, V. Effects of Brazilian and Bulgarian propolis on bactericidal activity of macrophages against Salmonella Typhimurium. International immunopharmacology, Amsterdam, v. 5, n. 2, p. 359-368, 2005a.

ORSI, R.O.; SFORCIN, J.M.; FUNARI, S.R.C.; FERNANDES JÚNIOR, A.; BANKOVA, V. Synergistic effect of propolis and antibiotics on the Salmonella Typhi. Brazilian Journal of Microbiology, São Paulo, v. 37, n. 2, p. 108-112, 2006.

ORSI, R.O.; SFORCIN, J.M.; RALL, V.L.M.; FUNARI, S.R.C.; BARBOSA, L.; FERNANDES JÚNIOR, A. Susceptibility profile of Salmonella against the antibacterial activity of propolis produced in two regions of Brazil. Journal of Venomous Animals and Toxins including Tropical Diseases, Botucatu, v. 11, n. 2, p. 109-116, 2005 b.

OUWEHAND, A.C.; SALMINEN, S.; ISOLAURI, E. Probiotics: an overview of beneficial effects. Antonie Van Leeuwenhoek, Wageningen, v. 82, n. 1/4, p. 279-289, 2002.

PAGE, S.W. Current use of antimicrobial growth promoters in food animals: The benefits. In: BARUG, D.; JONG, J.; KIES, A.K.; VERSTEGEN, M. (Ed.). Antimicrobial Growth Promoters: Where Do We Go from Here? Wageningen: Wageningen Academic Publishers, 2006, p. 19-51.

PARK, Y.K.; KOO, M.H.; SATO, H.H.; CONTADO, J.L. Estudo de alguns componentes da própolis coletada por Apis mellifera no Brasil. Arquivos de Biologia e Tecnologia, Curitiba, v. 38, n. 4, p. 1253-1259, 1995. 
PEDROSO, A.A.; OETTING, L.L.; UTIYAMA, C.E.; MENTEN, J.F.M.; LAMBAIS, M. R.; MIYADA, V.S. Variabilidade espacial da comunidade bacteriana intestinal de suínos suplementados com antibióticos ou extratos herbais. Revista Brasileira de Zootecnia, Viçosa, v. 34, n. 4, p. 1225-1233, 2005.

PINTO, M.S.; FARIA, J.E.; MESSAGE, D.; CASSINI, S.T.A.; PEREIRA, C.S.; GIOSO, M.M. Efeito de extrato de própolis verde sobre bactérias patogênicas isoladas do leite de vacas com mastite. Brazilian Journal of Veterinary Research and Animal Science, São Paulo, v. 38, n. 6, p. 278-283, 2001.

RASTALL, R.A. Bacteria in the gut: friends and foes and how to alter the balance. Journal of Nutrition, Philadelphia, v. 134, suppl. 8, p. 2022-2026, 2004.

ROBERT, S.; WEARY, D.M.; GONYOU, H. Segregated early weaning and welfare of piglets. Journal of Applied Animal Welfare Science, Mahwah, v. 2, n. 1, p. 31-40, 1999.

ROE, M.T.; PILLAI, S.D. Monitoring and identifying antibiotic resistance mechanisms in bacteria. Poultry Science, Oxford, v. 82, n. 4, p. 622-626, 2003.

ROSS, G.R.; GUSILS, C.; OLISZEWSKI, R.; DE HOLGADO, S.C.; GONZÁLEZ, S.N. Effects of probiotic administration in swine. Journal of bioscience and bioengineering, Osaka, v. 109, n. 6, p. 545-549, 2010.

RUFINO, M.S.M.; ALVES, R.E.; BRITO, E.S.; MORAIS, S.M.; SAMPAIO, C.G.; PÉREZJIMENEZ, J.; SAURA-CALIXTO, F. Metodologia científica: determinação da atividade antioxidante total em frutas pela captura do radical livre ABTS+. Fortaleza, jul., 2007. ( Comunicado Técnico, 128.)

RUFINO, M.S.M.; ALVES, R.E.; BRITO, E.S.; MORAIS, S.M.; SAMPAIO, C.G.; PÉREZJIMENEZ, J.; SAURA-CALIXTO, F. Metodologia científica: determinação da atividade antioxidante total em frutas pela captura do radical livre $\mathrm{ABTS}^{+}$. Fortaleza, jul., 2007.(Comunicado Técnico, 128.)

SAKOMURA, N.K.; ROSTAGNO, H.S. Métodos de pesquisa em nutrição de monogástricos. Jaboticabal: Funep, 2007. 283p.

SALATINO, A.; FERNANDES-SILVA, C.C.; RIGHI, A.A.; SALATINO, M.L.F. Propolis research and the chemistry of plant products. Natural Products Report, London, v. 28, p. 925-936, 2011.

SALEHA, A.A.; MIYANG, T.T.; GANAPATHY, K.K.; ZULKIFLI, I.; RAHA, R.; ARIFAH, K. Possible effect of antibiotic-supplemented feed and environment on the occurrence of multiple antibiotic resistant Escherichia coli in chickens. International Journal of Poultry Science, Faisalabad, v. 8, n. 1, p. 28-31, 2009.

SANCHEZ, M.; GALARDI, R. Influencia del propoleo en la conversión de lechones destetados. In: SIMPOSIO SOBRE LOS EFECTOS DEL PROPOLEO EN LA SALUD HUMANA Y ANIMAL, 1., 1988, Varadero. Anais... Varadero: Consejo Científico del Instituto de Medicina Veterinária, 1988. p. 211-214. 
SANTOS, W.G.; FILGUEIRAS, E.P.; BERTECHINI, A.G.; FIALHO, E.T.; LIMA, J.A. F.; BRITO, M.A.V.P. Manose na alimentação de leitões na fase de creche (desempenho, $\mathrm{pH}$ do trato gastrintestinal e peso dos órgãos). Ciência e Agrotecnologia, Lavras, v. 27, n. 3, p. 696-702, 2003.

SCANDOLERA, A.J.; THOMAZ, M.C.; KRONKA, R.N.; BUDIÑO, F.E.L.; FRAGA, A. L.; HUAYNATE, R. A.R.; RUIZ, U.S.; CRISTANI, J. Hidrolisados proteicos de mucosa intestinal, levedura e proteína isolada de soja em dietas com leite em pó integral para leitões desmamados. Revista Brasileira de Zootecnia, Viçosa, v. 37, n. 4, p. 2355-2368, 2008.

SCHAREK, L.; GUTH, J.; REITER, K.; WEYRAUCH, K.D.; TARAS, D.; SCHWERK, P.; SCHIERACK, P.; SCHMIDT, M.F.; WIELER, L.H; TEDIN, K. Influence of a probiotic Enterococcus faecium strain on development of the immune system of sows and piglets. Veterinary Immunology Immunopathology, New York, v. 105, n. 1/2, p. 151-161, 2005.

SEIDEL, V.; PEYFOON, E.; WATSON, D.G.; FEARNLEY, J. Comparative study of the antibacterial activity of propolis from different geographical and climatic zones.

Phytotherapy Research, London, v. 22, n. 9, p. 1256-1263, 2008.

SFORCIN, J.M.; BANKOVA, V. Propolis: Is there a potential for the development of new drugs? Journal of Ethnopharmacology, Lausanne, v. 133, n. 2, p. 253-260, 2011.

SFORCIN, J.M.; FERNANDES JÚNIOR, A.; LOPES, C.A.M.; BANKOVA, V.; FUNARI, S.R.C. Seasonal effect of Brazilian propolis antibacterial activity. Journal of Ethnopharmacology, Lausanne, v. 73, n. 1/2, p. 243-249, 2000.

SFORCIN, J.M.; FERNANDES JÚNIOR., A.; LOPES, C.A.M.; FUNARI, S.R.C.; BANKOVA, V. Seasonal effect of Brazilian propolis on Candida albicans and Candida tropicalis. Journal of Venomous Animals and Toxins, Botucatu, v. 7, n. 1, p. 139-144, 2001.

SHAHRYAR, H.A.; NAMVARI, M.; NOUROLLAHI, H.; SHADDEL, T.A. Effect of alcoholic extract propolis in immune system in broiler chickens. Journal of Basic and Applied Scientific Research, Cairo, v. 1, n. 11, p. 2094-2097, 2011.

SHALMANY, S.K.; SHIVAZAD, M. The effect of diet propolis supplementation on Ross broiler chicks performance. International Journal of Poultry Science, Faisalabad, v. 5, n. 1, p. 84-88, 2006.

SILVA, A.M.R.; BERTO, D.A.; LIMA, G.J.M.M.; WECHSLER, F.S.; PADILHA, P. M.; CASTRO, V.S. Valor nutricional e viabilidade econômica de rações suplementadas com maltodextrina e acidificante para leitões desmamados. Revista Brasileira de Zootecnia, Viçosa, v. 37, n. 2, p. 286-295, 2008.

SILVA, C.A.; BRIDI, A.M.; CASTRO-GOMEZ, R.J.H.; SILVA, C.R.B.; MENEGUCCI, C.G.;CARVALHO, B.B. Uso de probiótico e de antibióticos na alimentação de leitões em fase de creche. Semina: Ciências Agrárias, Londrina, v. 28, n. 4, p. 739-746, 2007.

SILVA, D.J.; QUEIROZ, A.C. Análise de alimentos: Métodos químicos e biológicos. 3.ed. Viçosa: Universidade Federal de Viçosa, 2006. 235p. 
SILVA, R.A.; RODRIGUES, A.E.; MARCUCCI, M. C.; CUSTÓDIO, A.R.; ANDRADE, N.E.D.; PEREIRA, W.E. Características físico-químicas e atividade antimicrobiana de extratos de própolis da Paraíba, Brasil. Ciência Rural, Santa Maria, v. 36, n. 6, p. 1842-1848, 2006.

SIMON, O. Micro-organisms as feed additives - probiotics. Advances in Pork Production, Edmonton, v. 16, p. 161-167, 2005.

SIMPSON, P.J.; FITZGERALD, G.F.; STANTON, C.; ROSS, R.P. The evaluation of a mupirocin-based selective medium for the enumeration of bifidobacteria from probiotic animal feed. Journal of Microbiological Methods, Amsterdam, v. 57, n. 1, p. 9-16, 2004.

SINGLETON, V.L.; ORTHOFER, R.; LAMUELA-RAVENTÓS, R.M. Analysis of total phenols and other oxidation substrates and antioxidants by means of Folin-Ciocalteau reagent. Methods of Enzymology, New York, v. 299, p. 152-178, 1999.

SMITH, H.W. Clinical problems of preventive medicine. World's Poultry Science Journal, Columbus, v. 31, n. 2, p. 104-115, 1975.

STEWART, C.S.; CHESSON, A. Making sense of probiotics. Pig Veterinary Journal, Malmesbury, v.31, p.11-33, 1993.

TALAS, Z.; GULHAN, M.; ERDOGAN, K.; ORUN, I. Antioxidant effects of propolis on carp Cyprinus carpio exposed to arsenic: biochemical and histopathologic findings. Diseases of Aquatic Organisms, Oldendorf/Luhe, v. 108, n. 3, p. 241-249, 2014.

TANNOCK, G.W. Influences of the normal microbiota on the animal host. In: MACKIE, R. L.; WHITE, B.A.; ISAACSON, R.E. (Ed.). Gastrointestinal Microbiology: Gastrointestinal microbes and host interactions. New York: Chapman \& Hall Microbiology Series, 1997. v. 2, p. $466-495$.

TARAS, D.; VAHJEN, W.; MACHA, M.; SIMON, O. Performance, diarrhea incidence, and occurrence of Escherichia coli virulence genes during long-term administration of a probiotic Enterococcus faecium strain to sows and piglets. Journal of Animal Science, Champaign, v. 84, n. 3, p. 608-617, 2006.

TARAS, D.; VAHJEN, W.; MACHA, M.; SIMON, O. Response of performance characteristics and fecal consistency to long-lasting supplementation with the probiotic strain Bacillus cereus var. toyoi to sows and piglets. Archives of Animal Nutrition, Abingdon, v. 59, n. 6, p. 405-417, 2005.

TATLI SEVEN, P.; YILMAZ, S.; SEVEN, I.; CERCI, I.H.; AZMAN, M.A.; YILMAZ, M. Effects of propolis on selected blood indicators and antioxidant enzyme activities in broilers under heat stress. Acta Veterinary Brno, Brno, v. 78, n. 1, p. 75-83, 2009.

TEKELI, A.; KUTLU, H. R.; ÇELIK, L. Effects of Z. officinale and propolis extracts on the performance, carcass and some blood parameters of broiler chicks. Current Research in Poultry Science, [s.1], v. 1, n. 1, p. 12-23, 2011. 
TORRES, C.R.G.; KUBO, C.H.; ANIDO, A.A.; RODRÍGUEZ, J.R. Antimicrobial agents and your potencial of use in odontology. Revista da Faculdade de Odontologia de São José dos Campos, São José dos Campos, v. 3, n. 2, p. 43-52, 2000.

VARGAS, A.C.; LOGUERCIO, A.P.; WITT, N.M.; COSTA, M.M.; SILVA, M.S.; VIANA, L.R. Atividade antimicrobiana "in vitro" de extrato etanólico de própolis. Ciência Rural, Santa Maria, v. 34, n. 1, p. 159-163, 2004.

VEIZAJ-DELIA, E.; PIU, T.; LEKAJ, P.; TAFAJ, M. Using combined probiotic to improve growth performance of weaned piglets on extensive farm conditions. Livestock Science, Amsterdam, v. 134, n. 1/3, p. 249-251, 2010.

WALSH, M.C.; GARDINER, G.E.; HART, O.M.; LAWLOR, P.G.; DALY, M.; LYNCH, B.; RICHERT, B.T.; RADCLIFFE, S.; GIBLIN, L.; HILL, C.; FITZGERALD, G.F.; STANTON, C.; ROSS, P. Predominance of a bacteriocin-producing Lactobacillus salivarius component of a five-strain probiotic in the porcine ileum and effects on host immune phenotype. FEMS

Microbiology Ecology, Amsterdam, v. 64, n. 2, p. 317-327, 2008.

WANG, A.; YU, H.; GAO, X.; LI, X.; QIAO, S. Influence of Lactobacillus fermentum I5007 on the intestinal and systemic immune responses of healthy and Escherichia coli challenged piglets. Antonie Van Leeuwenhoek, Wageningen, v. 96, n. 1, p. 89-98, 2009.

WEGENER, H.C. Antibiotics in animal feed and their role in resistance development. Current Opinion in Microbiolgy, London, v. 6, n. 5, p. 439-445, 2003.

WILLIAMS, R.J.; SPENCER, J.P.; RICE-EVANS, C. Flavonoids: antioxidants or signaling molecules? Free Radical Biology and Medicine, New York, v.36, n.7, p. 838-849, 2004.

WOJTYCZKA, R.D.; KEPA, M.; IDZIK, D.; KUBINA, R.; KABAŁA-DZIK, A.; DZIEDZIC, A.; WAsSIK, T.J. In vitro antimicrobial activity of ethanolic extract of polish propolis against biofilm forming Staphylococcus epidermidis strains. Evidence-based Complementary and Alternative Medicine, Oxford, v. 2013, p. 1-11, 2013.

ZEYNER, A.; BOLDT, E. Effects of a probiotic Enterococcus faecium strain supplemented from birth to weaning on diarrhoea patterns and performance of piglets. Journal of Animal Physiology and Animal Nutrition, Berlin, v. 90, n. 1/2, p. 25-31, 2006.

ZHANG, Z.F.; LEE, J.M.; KIM, I.H. Effects of Enterococcus faecium DSM 7134 on weanling pigs were influenced by dietary energy and crude protein density. Livestock Science, Amsterdam, v. 169, p. 106-111, 2014. 